Article

\title{
Comparative Study of the Heat and Mass Transfer Characteristics between Counter-Flow and Cross-Flow Heat Source Towers
}

\author{
Yifei $\mathrm{Lv}^{1}$, Jun Lu ${ }^{1, *}$, Yongcai $\mathrm{Li}^{1}$, Ling Xie ${ }^{1}$, Lulu Yang ${ }^{1}$ and Linlin Yuan ${ }^{2}$ \\ 1 School of Civil Engineering, Chongqing University, Chongqing 400044, China; yifei9679@sina.com (Y.L.); \\ liy30@cqu.edu.cn (Y.L.); cquxieling@cqu.edu.cn (L.X.); yanlulu@cqu.edu.cn (L.Y.) \\ 2 Commission for Discipline Inspection of Nankai District, Tianjin 300100, China; cqulemyuan@sina.com \\ * Correspondence: lujun66@vip.sina.com
}

Received: 23 March 2020; Accepted: 20 May 2020; Published: 26 May 2020

\begin{abstract}
The heat source tower (HST), as a cleaner energy production, which can absorb the low-grade energy from ambient air to drive the heat pump unit without emissions has attracted more and more interest. In addition, HST has excellent economic applicability by using cooling tower equipment, which was idle in winter. However, there are few studies on comparative analysis of thermal behavior between counter-flow and cross-flow HST. A mathematical model suitable for both HST types was developed to identify the performance discrepancies between them. Then a parametric study was carried out in order to investigate the impact of solution and air as well as packing material properties on energy transfer of HSTs. Finally, the characteristics of solution dilution and dehumidification were investigated. As the inlet solution temperature increases, increases first, then decreases gradually, but a transition point occurs in the solution at $-5{ }^{\circ} \mathrm{C}$. Moreover, the transition section of moisture transfer direction for counter-flow HST was located in the $0.78 \mathrm{~m}$ and $0.26-1.56 \mathrm{~m}$ of packing material height, under the condition that the air relative humidity was $50 \%$. In summary, this work intuitively indicates the thermal performance difference between counter-flow and cross-flow HST, also could assist the selection of proper operating conditions in HSTs.
\end{abstract}

Keywords: heat source tower; sensible heat transfer; latent heat transfer

\section{Introduction}

A heat source tower (HST), also known as a reversibly used cooling tower (RUCT) [1-3], absorbs low-grade energy from the air and supplies the heat to a building. It is generally believed that the heating tower is applicable in multiple countries and regions, especially for areas with high outdoor temperatures and humidity [4]. HST has several advantages compared with traditional heating units. One of the advantages is that HST can absorb low-grade energy from the atmosphere. In addition, the heat pump unit can drive low-level energy, which is more environmentally friendly. Furthermore, the conventional heating unit produces a series of toxic and harmful substances through combustion, which seriously affects the natural environment [5]. Hence, recent concerns about environmental pollution have greatly increased the attention paid to cleaner heating units like HST.

In fact, the thermal behavior discrepancies between cooling towers and HSTs are on account of several aspects. First, the direction of energy transfer is reversed. A cooling tower removes the excess heat from a building during the summer, while on the contrary, heat is applied to meet the user demand in winter [6]. The thermal behavior of the tower depends on different air properties, which are determined by the season. Second, prior studies have revealed that the thermal performance of HSTs is quite different from that of cooling towers $[7,8]$, mainly caused by different types of circulating 
heat transfer media $[9,10]$. Third, latent heat transfer (LHT) exists in HSTs but not in cooling towers. Hence, there remains a need for investigation of the thermal behavior on HSTs. Zhang et al. [11] developed an optimization index of the mismatch coefficient $\gamma$, which can measure the influence of inlet parameters on the solution dehumidification module, and it also used for fluid flow channel and thermal performance optimization. Three typical flow channels were compared, and the results showed that the heating supply temperature can be decreased by $15^{\circ} \mathrm{C}$ through optimization. System performance optimization studies of HSTs were also conducted by Zhang et al. [12], who experimentally and theoretically discussed the influence of mass transfer unit number $N T U_{m}$ on the thermal performance of a HST, and when the $N T U_{m}$ taken as 4, the optimal value of HST energy transfer is obtained. Further, the HST system COP can be increased by using an inter-stage cycle value under 3.5. Cui and Li [2,3], carried out some studies on spray HST, where the thermal behavior of the HST was studied comparing between downward spray and upward spray through parameter analysis. The results pointed out that downward gas-flow and upward solution-flow are beneficial to enhance the energy transfer, moreover, smaller droplet diameters have a significant effect on the thermal performance of a HST. At the same time, micro-scale heat transfer also has a significant impact on the heat transfer performance of HSTs. Many numerical studies have shown that wettability of the solid surface $[13,14]$ and nature roughness of solid surface [15] have a significant effect on the heat flux of the system.

Tan and Deng's research [16] was based on cooling towers, but it provides a fundamental basis for studying the thermal performance of HSTs, and a mathematical model suitable for HST was proposed. However, the cross-section properties cannot be calculated through this model. Besides, this model was only suitable for calculating counter-flow HSTs. In order to address this limitation, Tan and Deng [9] established the HST model, but like Huang et al. [17], this model does not consider Lewis numbers. Further, a mathematical model coupling Lewis number and energy transfer was proposed by Zhang et al. [6]. Since Lewis number is considered, this model is more accurate. Furthermore, many studies were based on this model. Wang et al. [18] experimentally determined the influence of air humidity on the energy transfer of HST, showing that the $\varepsilon$-NTU model is not suitable for extremely high air humidity conditions by increasing the air humidity ratio from $20 \mathrm{~g} \cdot \mathrm{kg}^{-1}$ to $160 \mathrm{~g} \cdot \mathrm{kg}^{-1}$ gradually. Song et al. [19] performed some optimization research based on $N T U_{m}$ under the above assumption. Prior studies have mainly focused on counter-flow HST or dehumidification modules, in order to better characterize the cross-flow HST.

Some studies were conducted on cross-flow HSTs. Wen et al. [20] numerically investigated the impact of air and solution properties on the energy transfer of a cross-flow HST. The results showed that the air-flow and solution-flow play a significant role in the energy transfer increase. Meanwhile, the effect of solution and air temperature on heat transfer are slight. Huang et al. [17] took glycol as a circulating heat transfer medium to experimentally study the system behavior and energy transfer characteristics without consideration of the Lewis number, and correlation expressions were presented using the solution mass flow and air mass flow. Given the above studies, there were some studies comparing the thermal behavior between counter-flow and cross-flow HSTs and the Lewis number effect. Huang et al. [21], identified the evolution of sensible heat and latent heat transfer characteristics with the gas-liquid ratio under low-temperature conditions. Their results indicated that HST system performance can be improved by adjusting the operating parameters. Liang et al. [22] claimed that the air inlet temperature has a greater effect on the solution regeneration rate of HSTs. Other studies [23] have found that HSTs have the risk of freezing during winter, which was caused by the solution, but there is few studies on the dilution and humidification characteristics of the solution in HSTs. Therefore, a new comparative discussion about the thermal behavior in counter-flow and cross-flow HSTs is necessary, including solution dilution and the humidification characteristics of the packing material.

The aim of our research is to identify the influence of air and solutions as well as packing material properties on the thermal behavior within HST. A mathematical model validated by experimental data was developed to predict the latent and sensible heat transfer of a HST. The influence of the properties 
on sensible and latent heat transfer was examined. Additionally, solution dilution and dehumidification characteristics were studied. This research could assist the selection of proper operating conditions for existing HSTs.

\section{Theoretical Model}

\subsection{Description of the Two Types of HST}

The schematic diagrams of the adiabatic cross-flow HST module and the counter-flow HST module are shown in Figure 1, respectively. The solutions are sprayed uniformly onto the packing materias from the top surface to the bottom of the HST by the nozzles. According to the air flow direction in the HST, HSTs are divided into two types. When air enters from the side and flows out from the opposite side it is a cross-flow HST, and if air enters from the bottom side and out of the top side it is a counter-flow HST. The energy transfer arises on the packing material between the solution and the air. When the HST is operating in summer, the air flows through the material in the HST, where the air is humidified and heated, so that the enthalpy of the air increases while the solution temperature decreases.

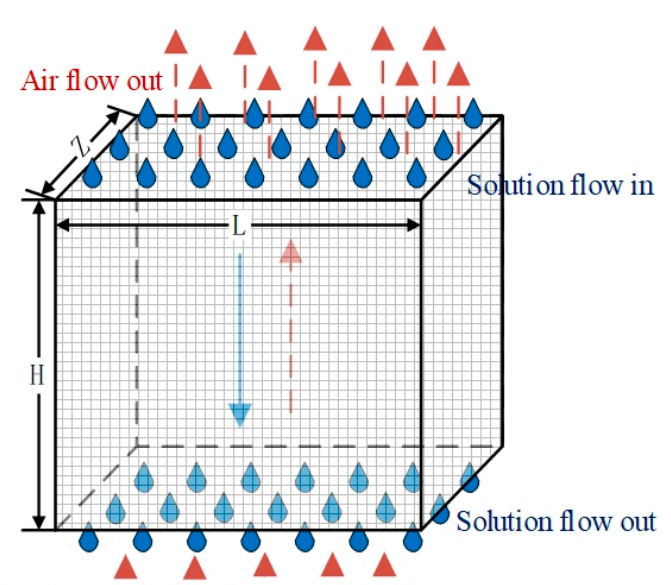

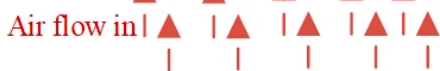

(a) Counter-flow

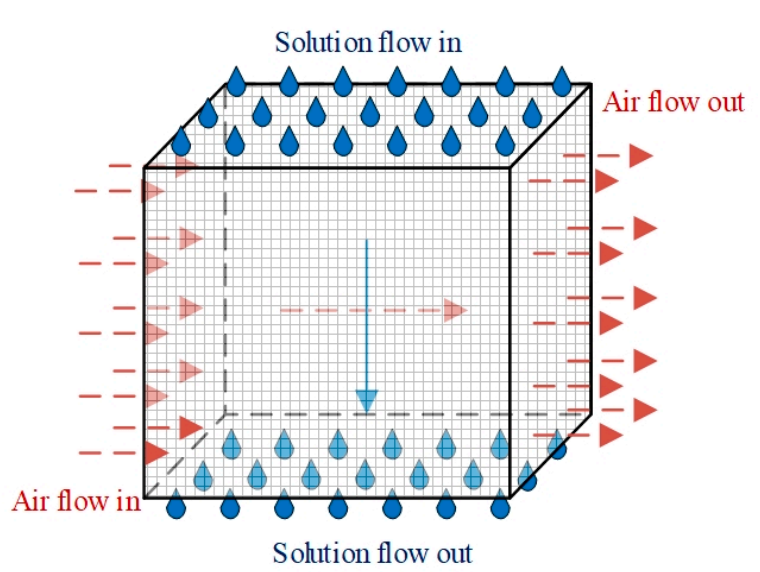

(b) Cross-flow

Figure 1. Schematic diagram of fluid flow direction in packing material. (a): Counter-flow (b): Cross-flow.

When the HST is operating in winter, the circulating heat transfer medium is replaced by an antifreeze solution with a freezing point below $0{ }^{\circ} \mathrm{C}$. Unlike a HST running in the summer, the air will be cooled and dehumidified, and the solution concentration is diluted while the temperature of the solution rises.

Figure 2 illustrates the operating mode of the HST system. The red arrow highlights the heating condition and the blue arrow outlines the cooling condition. When the HST system is operating during the summer, the cooling of the circulating heat transfer medium was carried out by direct evaporation. After pumping the cooling water to the condenser, the heat released by the heat transfer circulating medium is absorbed by the refrigerant in the compressor, and then the circulating cooling water flows out of the condenser.

The HST system collects low-grade heat energy in the outdoor air in winter, the circulating heat transfer medium is an aqueous solution of calcium chloride. The antifreeze solution flows out of the heat pump unit and then flows into the HST. After absorbing heat from the air, the solution enters the evaporator through the water pump, the refrigerant gains heat through the phase change process, and the circulating process occurs again to transfer the heat. 


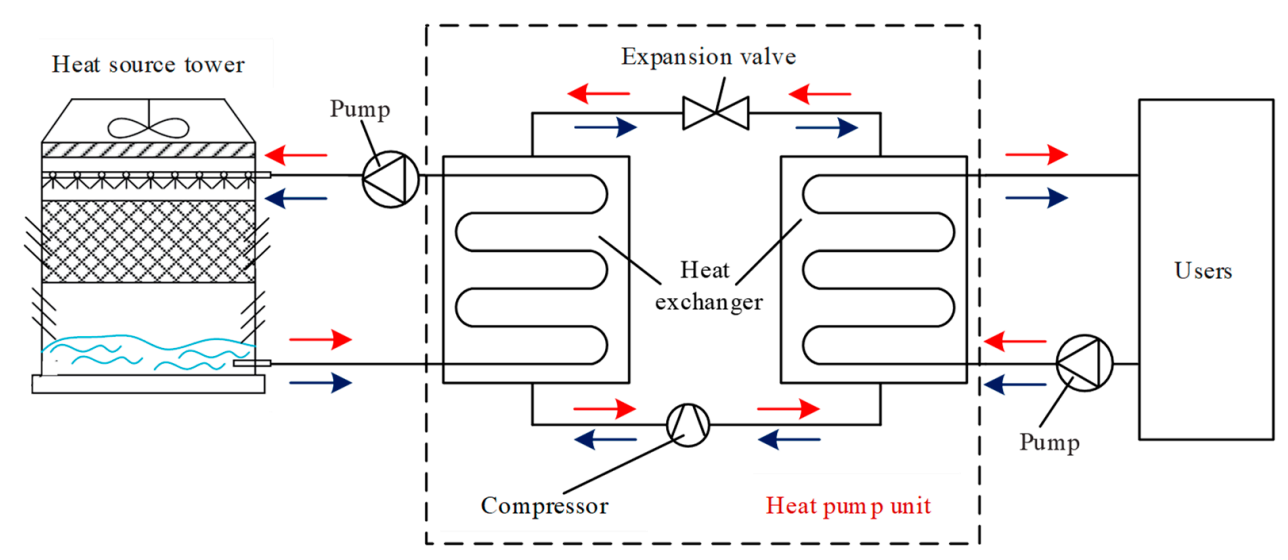

Figure 2. Schematic of the HST operating mode.

\subsection{Establishment of Mathematical Equations}

A mathematical model was developed to investigate the thermal performances of cross-flow and counter-flow HSTs. The major simplifications and assumptions for the mathematical model are as follows:

(1) The specific heat and density are constant with temperature [12,20];

(2) The heat and mass exchange through the tower surface to the environment are negligible;

(3) Heat and mass transfer perpendicular to the flow direction is ignored;

(4) The thermal resistance between the solution and the air occurs on the airside;

(5) The properties of the packing material are uniform and stable;

(6) There is no loss of solute during HST operation;

(7) Both inlet air and solution flow rates are steady and uniform.

Based on the above assumptions, the cross-flow HST can be simplified into a two-dimensional model, and the counter-flow HST can be simplified into a one-dimensional model. Because both the inlet air and solution flow rates are steady and uniform, any one of the control volumes can be selected for analysis throughout the entire model. The control volumes of a cross-flow and counter-flow HST are shown in Figure 3.
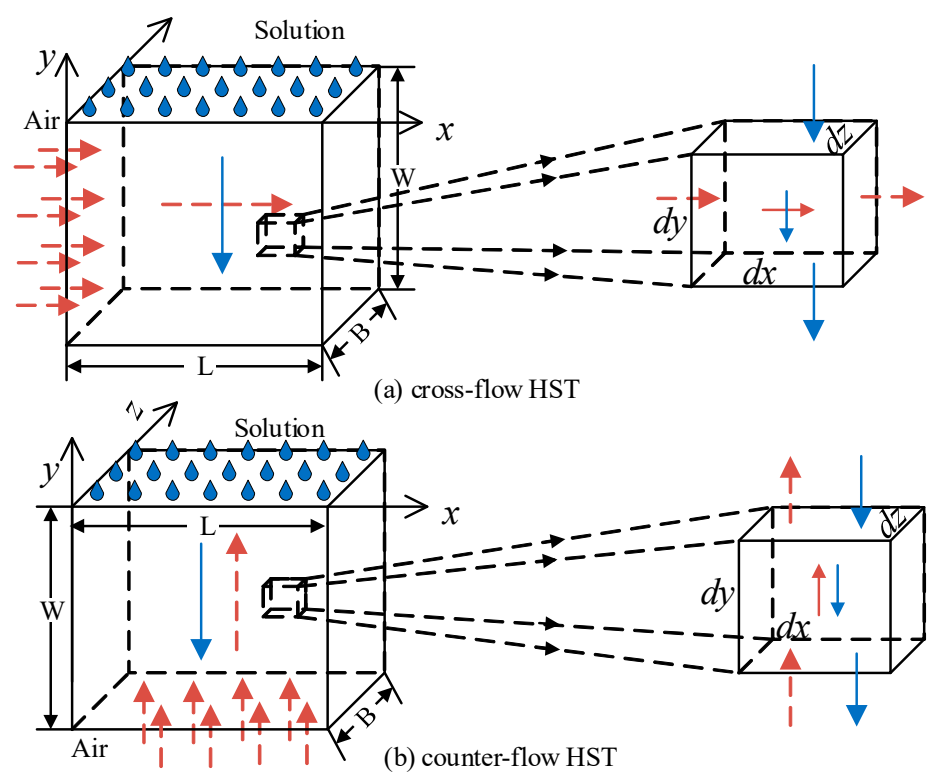

Figure 3. Schematic diagram of the cross-flow and counter-flow HST control volume. 


\subsubsection{Development of Governing Equations}

The control volume is shown in Figure 3. Every control volume follows the conservation of energy. Therefore, for any of the control volumes, there are the following rules: The value of variables that fluids enter the control volume + the increment of variables produced by the interaction between control volume and fluids = the value of variables that fluids leave the control volume + the cumulative value of variables in the control volume. The packing material is thermally insulated and has no internal heat source inside, and then the energy is completely released between the air and the solution. Therefore, the energy generated and accumulated by the control volume is none [6].

Extracted to the conservation of energy, the enthalpy of the inlet and outlet should be equal, thus, which can be written as Equation (1):

$$
H_{0}-H_{i}=0
$$

The input enthalpy of the control volume can be written as below:

$$
H_{i}=\frac{m_{a} H_{a}}{W B} d y d z d x+\frac{m_{s} H_{s}}{L W} d x d z d y
$$

The output enthalpy of the control volume can be written as Equation (3):

$$
H_{o}=\left(\frac{m_{a} H_{a}}{W B}+\frac{\partial \frac{m_{a} H_{a}}{W B}}{\partial x}\right) d y d z d x+\left(\frac{m_{s} H_{s}}{L W}+\frac{\partial \frac{m_{s} H_{s}}{L W}}{\partial y}\right) d x d z d y
$$

Combining Equations (2) and (3), the energy conservation equation of the control volume can be rewritten as Equation (4):

$$
\frac{1}{B} \cdot \frac{\partial}{\partial x}\left(m_{a} H_{a}\right)+\frac{1}{L} \cdot \frac{\partial}{\partial y}\left(m_{s} H_{s}\right)=0
$$

The mass of water brought into the control volume by air and solution is equal to that of water brought out of the control volume by air and solution. Similarly, the water vapor mass balance equation can be written as Equation (5):

$$
\frac{m_{s} \omega_{s}}{L W} d x d z d y-\left(\left(\frac{m_{a} \omega_{a}}{W B}+\frac{\partial \frac{m_{a} \omega_{a}}{W B}}{\partial x}\right) d y d z d x+\left(\frac{m_{s} \omega_{s}}{L W}+\frac{\partial \frac{m_{s} \omega_{s}}{L W}}{\partial y}\right) d x d z d y\right)=0
$$

Simplifying Equation (5) we get Equation (6):

$$
\frac{1}{B} \frac{\partial}{\partial x}\left(m_{a} \omega_{a}\right)+\frac{1}{L} \cdot \frac{\partial m_{s}}{\partial y}=0
$$

It is assumed that the solute of the antifreeze solution does not change, that is, the solute has no loss [24], then Equation (7) can be written as:

$$
d\left(m_{s} \zeta\right)=0
$$

where $\zeta$ is the solute mass fraction of the antifreeze solution, $\%$.

As can be seen from above, the properties of the packing material are uniform and stable. Assume that $\mathrm{A}$ is packing material heat and mass transfer surface. According to the literature, the value can be calculated as Equation (8):

$$
A=\frac{\beta L W B}{D}
$$

where $\beta$ is the packing material porosity, it is the ratio of the void volume of the total volume. $D$ is the packing material spacing, $m$. During the energy transfer process, the energy transfer of the air is caused by two effects. On the one hand, convective heat transfer occurs between air and solution. 
On the other hand, the water vapor undergoes a phase change process, the air condenses and liquefies and rapidly releases the latent heat of condensation.

So, the energy transfer equation of the control volume can be written as Equation (9):

$$
\frac{\partial \frac{m_{a} H_{a}}{W B}}{\partial x} d x d y d z=h_{c} \frac{A}{L W B}\left(T_{s}-T_{a}\right) d x d y d z+r \frac{\partial \frac{m_{a} \omega_{a}}{W B}}{\partial x} d x d y d z
$$

Simplifying Equation (9) we get Equation (10):

$$
\frac{\partial\left(m_{a} H_{a}\right)}{\partial x}=h_{c} \frac{A}{L}\left(T_{s}-T_{a}\right)+r \frac{\partial\left(m_{a} \omega_{a}\right)}{\partial x}
$$

Similarly, during the mass transfer process, the difference in air humidity ratio is due to the convective mass transfer process, so the control volume moisture transfer equation can be written as Equation (11):

$$
\frac{\partial \frac{m_{a} \omega_{a}}{W B}}{\partial x} d y d z d x=h_{m} \frac{A}{L W B}\left(\omega_{s}-\omega_{a}\right) d x d y d z
$$

Simplifying Equation (11) we get Equation (12):

$$
\frac{\partial\left(m_{a} \omega_{a}\right)}{\partial x}=h_{m} \frac{A}{L}\left(\omega_{s}-\omega_{a}\right)
$$

The enthalpy difference between moist air can be written as Equation (13):

$$
c_{p}\left(T_{s}-T_{a}\right)+r\left(\omega_{s}-\omega_{a}\right)=H_{s}-H_{a}
$$

where $C_{p}$ is specific heat of air $\left(\mathrm{kJ} \cdot \mathrm{kg}^{-1} \cdot \mathrm{K}^{-1}\right)$ and $r$ is water latent heat of condensation at $0{ }^{\circ} \mathrm{C}$ $\left(\mathrm{kJ} \cdot \mathrm{kg}^{-1} \cdot \mathrm{K}^{-1}\right)$. The mass transfer unit number $N T U_{m}$ is a dimensionless number that measures the heat transfer capacity within different fluids. The Lewis number Le representing the ratio of thermal diffusion coefficient to the mass diffusion coefficient. It describes the extent of heat transfer and mass transfer during convective heat transfer. The $N T U_{m}$ and the Le can be written as Equations (14) and (15):

$$
\begin{gathered}
\frac{h_{m} A}{m_{a}}=N T U_{m} \\
L e=\frac{h_{c}}{h_{m} c_{p}}
\end{gathered}
$$

The transfer coefficient varies linearly. $C_{p}$ represents the specific heat of air $\left(\mathrm{kJ} \cdot \mathrm{kg}^{-1} \cdot \mathrm{K}^{-1}\right), h_{m}$ is the evaporation coefficient. Combined with Equations (12)-(17) this becomes:

$$
\begin{gathered}
\frac{\partial H_{a}}{\partial x}=L e \frac{N T U_{m}}{S}\left(H_{s}-H_{a}+r\left(\frac{1}{L e}-1\right)\left(\omega_{s}-\omega_{a}\right)\right) \\
\frac{\partial \omega_{a}}{\partial x}=\frac{N T U_{m}}{S}\left(\omega_{s}-\omega_{a}\right)
\end{gathered}
$$

Equations (4), (6), (7), (16) and (17) establish the major energy transfer model in a cross-flow HST. Therefore, through similar steps, the counter-flow conservation of energy Equation (18) can be rewritten as below:

$$
\frac{m_{a} H_{a}}{L W} d x d z d y+\frac{m_{s} H_{s}}{L W} d x d z d y=\left(\frac{m_{a} H_{a}}{L W}+\frac{\partial \frac{m_{a} H_{a}}{L W}}{\partial y}\right) d x d z d y+\left(\frac{m_{s} H_{s}}{L W}+\frac{\partial \frac{m_{s} H_{s}}{L W}}{\partial y}\right) d x d z d y
$$


The counter-flow mass conservation can be written as Equation (19):

$$
\frac{m_{a} \omega_{a}}{L W} d x d z d y+\frac{m_{s} \omega_{s}}{L W} d x d z d y-\left(\left(\frac{m_{a} \omega_{a}}{L W}+\frac{\partial \frac{m_{a} \omega_{a}}{L W}}{\partial y}\right) d x d z d y+\left(\frac{m_{s} \omega_{s}}{L W}+\frac{\partial \frac{m_{s} \omega_{s}}{L W}}{\partial y}\right) d x d z d y\right)=0
$$

The heat transfer process can be written as Equation (20):

$$
\frac{\partial \frac{m_{a} H_{a}}{L W}}{\partial y} d x d y d z=h_{c} \frac{A}{L W B}\left(T_{s}-T_{a}\right) d x d y d z+r \frac{\partial L W}{\partial y} d x d y d z
$$

The mass transfer process can be written as Equation (21):

$$
\frac{\partial \frac{m_{a} \omega_{a}}{L W}}{\partial y} d x d y d z=h_{m} \frac{A}{L W B}\left(\omega_{s}-\omega_{a}\right) d x d y d z
$$

Taking Equation (16) into Equations (20) and (21), and then simplifying it with Equations (18) and (19), the conservation of energy can be rewritten as Equation (22):

$$
m_{a} \frac{\partial}{\partial y}\left(H_{a}\right)+\frac{\partial}{\partial y}\left(m_{s} H_{s}\right)=0
$$

The mass balance equation can be rewritten as Equations (23) and (24):

$$
\begin{gathered}
\frac{\partial}{\partial y}\left(m_{a} \omega_{a}+m_{s}\right)=0 \\
d\left(m_{s} \zeta\right)=0
\end{gathered}
$$

The heat transfer process can be rewritten as Equation (25):

$$
\frac{\partial H_{a}}{\partial y}=L e \frac{N T U_{m}}{B}\left(H_{s}-H_{a}+r\left(\frac{1}{L e}-1\right)\left(\omega_{s}-\omega_{a}\right)\right)
$$

The mass transfer process can be rewritten as Equation (26):

$$
\frac{\partial \omega_{a}}{\partial y}=\frac{N T U_{m}}{B}\left(\omega_{s}-\omega_{a}\right)
$$

\subsubsection{Numerical Methods}

In order to solve the equation using the finite difference method, the governing equation is rewritten into the form of a differential equation $[25,26]$.

Figure 4 explains method intuitively. The section can be seen as a two-dimensional mathematical model, which divides the packing material into $\mathrm{N}$ parts of the $x$ direction and into K parts of the $y$ direction. For any control volume $(i, j)$ in this model, the input parameters are the enthalpy of the solution $h_{s}{ }^{i, j}$, air enthalpy $h_{a}{ }^{i, j}$, solution mass flow rate $m_{s}{ }^{i, j}$, air humidity ratio $\omega_{a}{ }^{i, j}$, and solution concentration $\zeta^{i, j}$, respectively. The output parameters are $h_{s}{ }^{i+1, j}, h_{a}{ }^{i, j+1}, m_{s}{ }^{i+1, j}, \omega_{a}^{i, j+1}, \zeta^{i+1, j}$ (where $i<\mathrm{K}, j<N)$.

For the $(i+1, j)$ or $(i, j+1)$ control volumes, the same calculation process is performed to obtain the import of the next volume, and then repeating the calculation process $[25,26]$. When the values of $\mathrm{K}$ and $\mathrm{N}$ are large enough, the result can be considered reliable [6]. 


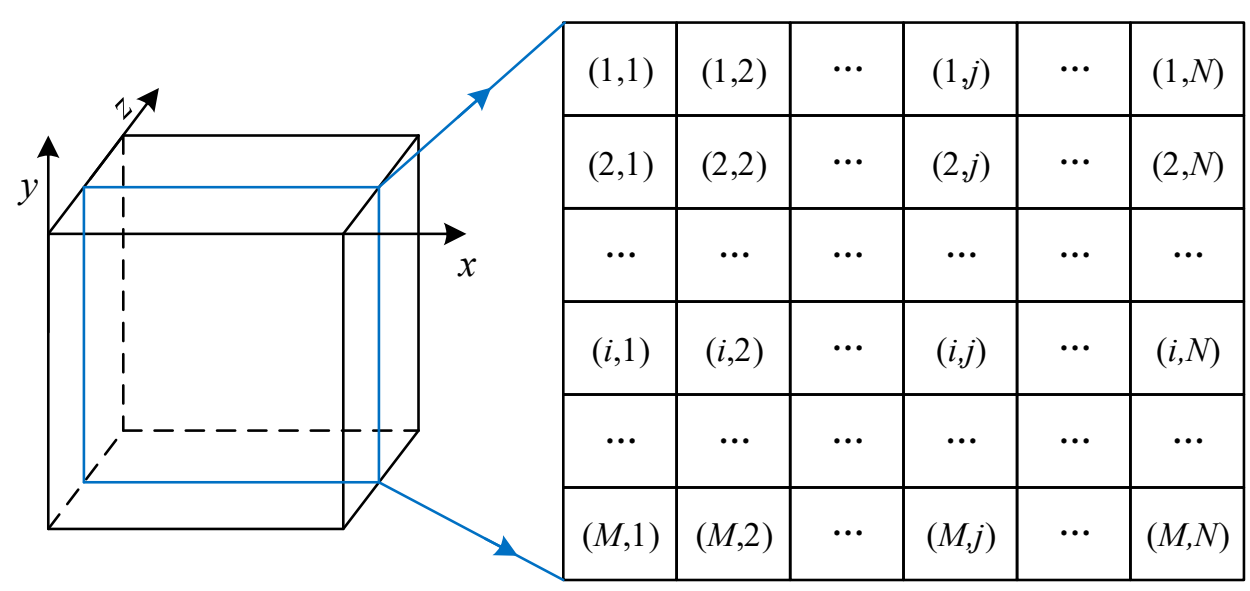

Figure 4. The finite difference method of cross-flow and counter-flow HST.

For mesh $(i, j)$, the Equations (22)-(26) can be discretized as follows:

$$
\begin{gathered}
m_{s}^{i+1, j} \zeta^{i+1, j}=m_{s}^{i, j} \zeta^{i, j} \\
N m_{a} H_{a}^{i, j+1}+K m_{s}^{i+1, j} H_{s}^{i+1, j}=N m_{a} H_{a}^{i, j}+K m_{s}^{i, j} H_{s}^{i, j} \\
N m_{a} \omega_{a}^{i, j+1}+K m_{s}^{i+1, j}=N m_{a} \omega_{a}^{i, j}+K m_{s}^{i, j} \\
h_{a}^{i, j+1}=h_{a}^{i, j}+L e \frac{N T U_{m}}{N}\left(h_{s}^{i, j}-h_{a}^{i, j}+r\left(\frac{1}{L e}-1\right)\left(\omega_{s}^{i, j}-\omega_{a}^{i, j}\right)\right) \\
\omega_{a}^{i, j+1}=\omega_{a}^{i, j}+\frac{N T U_{m}}{N}\left(\omega_{s}^{i, j}-\omega_{a}^{i, j}\right)
\end{gathered}
$$

This model uses an aqueous solution of calcium chloride as fluid. The boundary layer generated while the solution contact with air, the energy transfer process occurs on the boundary layer, simultaneously. The humidity ratio of moist air in the boundary layer can be written as Equation (32):

$$
\omega_{s}=\omega_{a, 0}=0.622 \frac{P_{f}}{P_{a t m}-P_{f}}
$$

The air enthalpy can be written as Equation (33):

$$
H_{a}=1.01 \times T_{a}+1001 \omega_{a}\left(2501+1.84 T_{a}\right)
$$

The enthalpy of solution can be written as Equations (34)-(36) [27]:

$$
\begin{gathered}
\Delta H_{s}=\Delta H_{s, o}\left[1+\left(\frac{\varphi}{\lambda_{1}}\right)^{\lambda_{2}}\right]^{\lambda_{3}} \\
\varphi=\frac{\zeta}{\lambda_{4}-\zeta} \\
\Delta h_{d, 0}=\lambda_{5}+\lambda_{6} \times T_{\text {sol }}
\end{gathered}
$$

The values of the correlation coefficients are shown in Table 1. Combining Equations (34)-(36) and Table 1, Equation (34) can be rewritten as below:

$$
\Delta H_{s}=\left(-955.69+3011.974 T_{s}\right)\left[1+\left(\frac{\zeta}{0.855(0.8-\zeta)}\right)^{-1.965}\right]^{-2.265}
$$


Table 1. The enthalpy calculation coefficient of calcium chloride [27]. Reproduced from [28], International Journal of Thermal Sciences: 2003.

\begin{tabular}{ccccccc}
\hline Coefficient & $\lambda_{1}$ & $\lambda_{2}$ & $\lambda_{3}$ & $\lambda_{4}$ & $\lambda_{5}$ & $\lambda_{6}$ \\
\hline Value & 0.855 & -1.965 & -2.265 & 0.8 & -955.690 & 3011.974 \\
\hline
\end{tabular}

\subsection{Determination of Other Parameters}

For both forms of HSTs, the solution specific heat and the packing $N T U_{m}$ are the same, so the two forms of packing materials can be discussed together.

\subsubsection{Solution Specific Heat}

For aqueous calcium chloride solutions in the non-crystalline region, the specific heat can be calculated using Equations (38)-(42) [27]:

$$
\begin{gathered}
\tau=\frac{T_{s}+273.15}{228}-1 \\
c_{p, H_{2} O}=\xi_{1}+\xi_{2} \tau^{0.02}+\xi_{3} \tau^{0.04}+\xi_{4} \tau^{0.06}+\xi_{5} \tau^{1.8}+\xi_{6} \tau^{8} \\
f_{1}\left(T_{s}\right)=a \tau^{0.02}+b \tau^{0.04}+c \tau^{0.06} \\
f_{2}(\zeta)=d \zeta+e \zeta^{2}+f \zeta^{3} \\
c_{p}=c_{p, H_{2} O}\left[1-f_{1}\left(T_{s}\right) f_{2}(\zeta)\right]
\end{gathered}
$$

where, $\xi_{i}(i=1,2, \ldots, 6), a-e$ and $f$ are all constant value, and their values areas below in Table 2.

Table 2. Constant value for calculating.

\begin{tabular}{cccccc}
\hline $\boldsymbol{a}$ & $\boldsymbol{b}$ & $\boldsymbol{c}$ & $\boldsymbol{d}$ & $\boldsymbol{e}$ & $f$ \\
\hline 58.5225 & -105.6343 & 47.7948 & 1.63799 & -1.69002 & 1.05124 \\
$\xi_{1}$ & $\xi_{2}$ & $\xi_{3}$ & $\xi_{4}$ & $\xi_{5}$ & $\xi_{6}$ \\
88.7891 & -120.1958 & -16.9264 & 52.4654 & 0.10826 & 0.46988 \\
\hline
\end{tabular}

\subsubsection{Packing Material $N T U_{m}$}

The mass transfer coefficient is difficult to determine in the Equation (14). And the relation between Sherwood number $(S h)$ and $\mathrm{hm}$ can be obtained from the following formula:

$$
h_{m}=\operatorname{Sh} \frac{\rho_{a} D_{a}}{d_{s}}
$$

in which $d_{s}$ is the equivalent diameter of the channel as defined by Al-Farayedhi et al. [28].

Therefore, the Sherwood number $(S h)$ was introduced into Equation (14). The Sherwood number of the packing material can be obtained by fitting the experimental data. So, $N T U_{m}$ can be rewritten as Equation (44):

$$
N T U_{m}=S h \frac{\rho_{a} D_{a} A}{m_{a} d_{s}}
$$

with Equations (8) and (43), then Equation (45) can be written as:

$$
N T U_{m}=S h \frac{\rho_{a} D_{a} \beta L W B}{m_{a} d_{s} D}
$$


2.3.3. Heat and Mass Transfer Coefficient

According to literature [26], the heat transfer coefficient $h_{c}$ can be calculated as follows:

$$
\begin{aligned}
& h_{m}=\frac{D_{a}}{D}\left(2+0.6 \operatorname{Re}^{1 / 2} S c^{1 / 3}\right) \\
& h_{c}=\frac{k_{a}}{D}\left(2.0+0.6 \operatorname{Re}^{1 / 2} \operatorname{Pr}^{1 / 3}\right)
\end{aligned}
$$

A program written in MATLAB (R2018b, The MathWorks, Inc., Natick, MA, USA) is used to solve the mathematical models. The computational flow of the program is illustrated below in Figure 5.

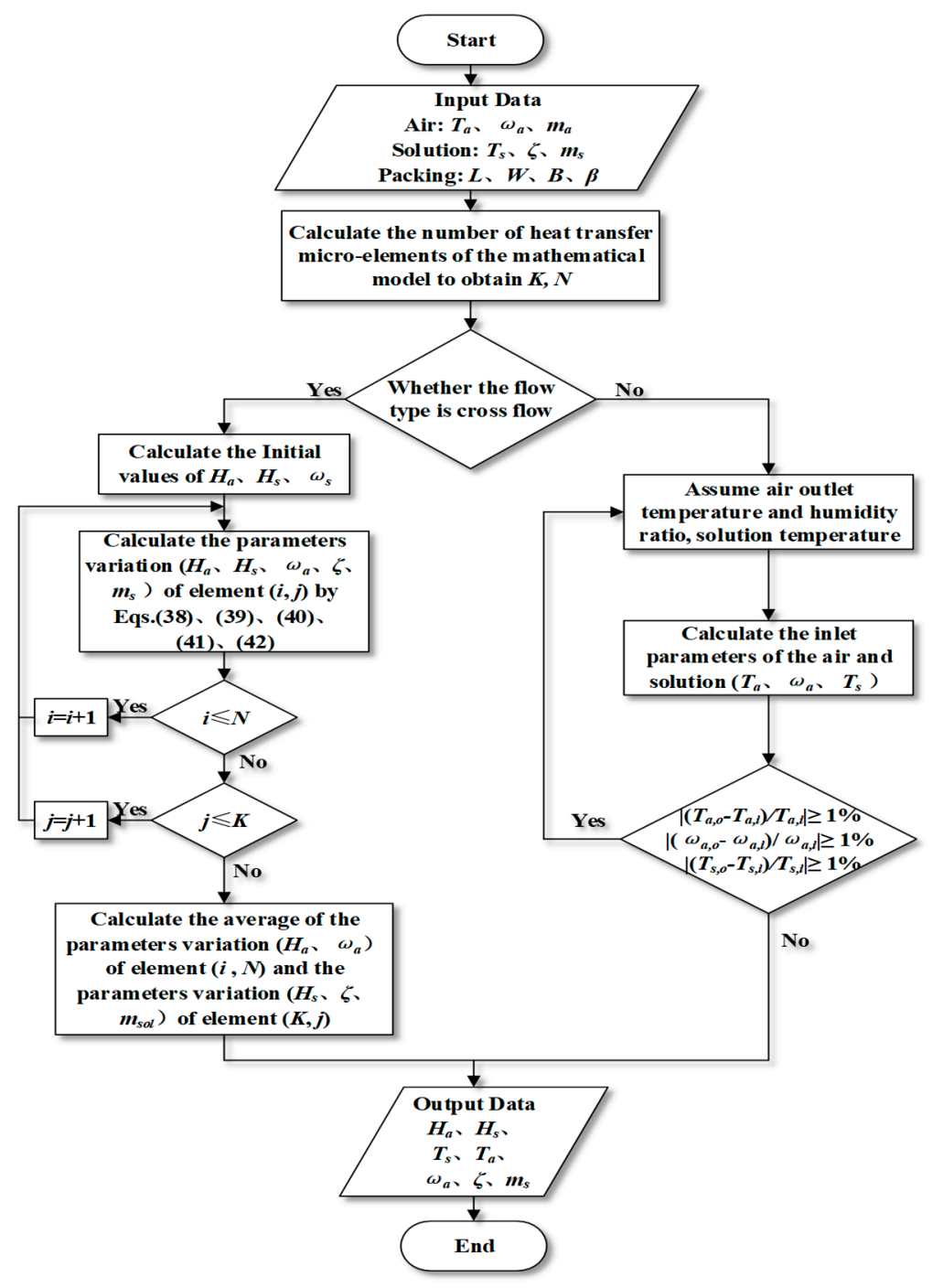

Figure 5. The flowchart of cross-flow and counter-flow HST program.

\section{Experiment and Model Verification of the HST}

To validate the developed mathematical model, field experimental work has been carried out by our group in Chongqing City. Figure 6 shows the major structure of the experimental platform. The experimental device used in the experiment is shown in Table 3. 


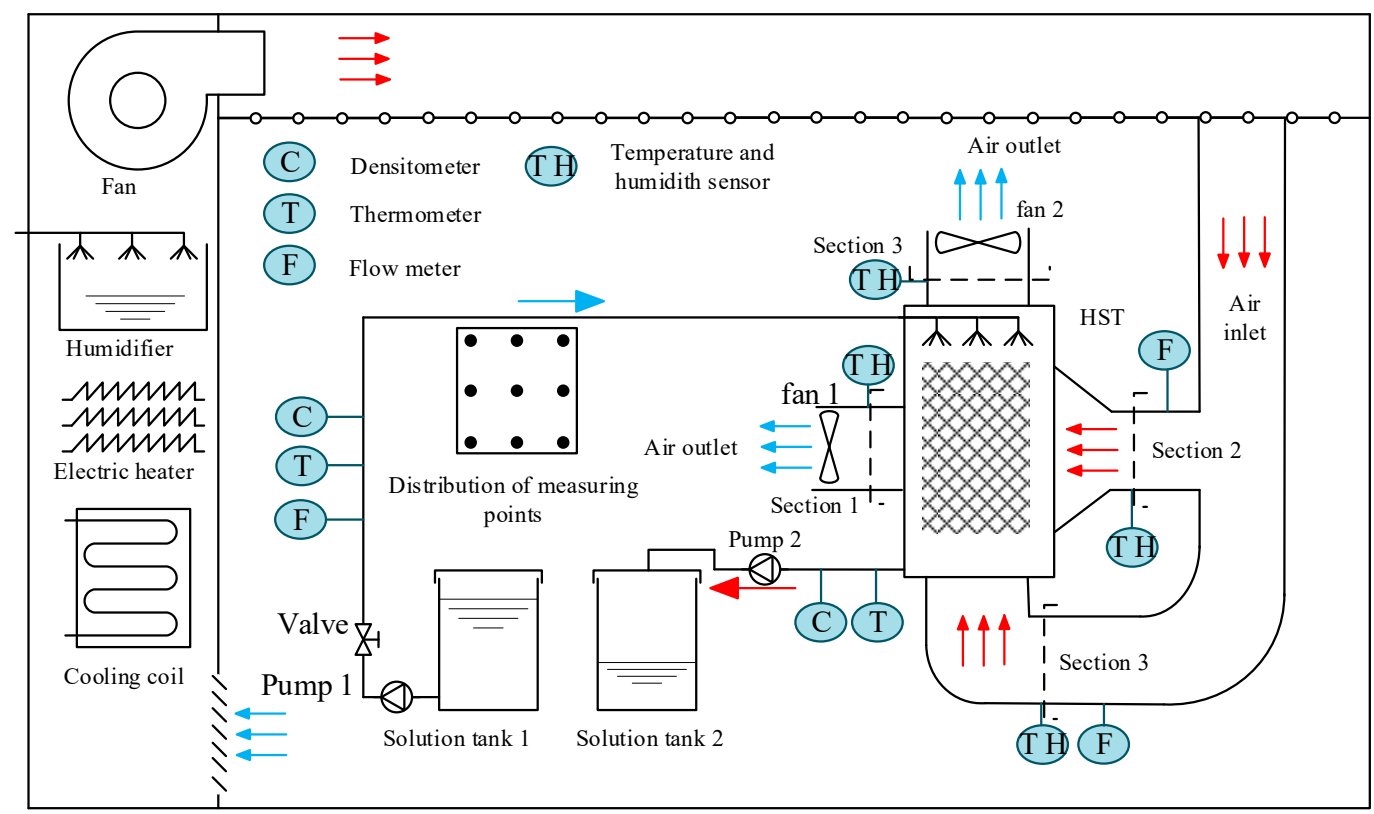

Figure 6. Schematic diagram of the experimental device setup.

Table 3. Experimental parameters and instruments.

\begin{tabular}{|c|c|c|c|c|c|}
\hline Parameters & Position & Instruments & Type & Accuracy & Range \\
\hline \multirow{4}{*}{ Air } & Flow rate & Rotary Anemometer & Testo & $\pm 0.03 \mathrm{~m} / \mathrm{s}$ & $0-20 \mathrm{~m} / \mathrm{s}$ \\
\hline & Inlet $T_{a, i}$ and & Temperature and & & $\mathrm{T}: \pm 0.5^{\circ} \mathrm{C}$ & $\mathrm{T}:-20.0^{\circ} \mathrm{C}-70.0^{\circ} \mathrm{C}$ \\
\hline & & Humidity Recorder & HIOKI 3641-20 & $\omega: \pm 5 \%$ & $\omega: 0.0-100.0 \%$ \\
\hline & $\begin{array}{c}\text { Outlet } T_{a, o} \text { and } \\
\omega_{a, o}\end{array}$ & $\begin{array}{l}\text { Temperature and } \\
\text { Humidity Recorder }\end{array}$ & HIOKI 3641-20 & $\begin{array}{c}T: \pm 0.5^{\circ} \mathrm{C} \\
\omega: \pm 5 \%\end{array}$ & $\begin{array}{c}\mathrm{T}:-20.0^{\circ} \mathrm{C}-70.0^{\circ} \mathrm{C} \\
\omega: 0.0-100.0 \%\end{array}$ \\
\hline \multirow{5}{*}{ Solution } & Flow rate & Ultrasonic Flow meter & DCT 1288 & $\pm 0.5 \%$ & $-12-12 \mathrm{~m} / \mathrm{s}$ \\
\hline & Inlet $T_{s, i}$ & Thermometer & Pt 100 & $\pm 1 \%$ & $-200^{\circ} \mathrm{C}-650^{\circ} \mathrm{C}$ \\
\hline & Outlet $T_{S, O}$ & Thermometer & Pt 100 & $\pm 1 \%$ & $-200{ }^{\circ} \mathrm{C}-650^{\circ} \mathrm{C}$ \\
\hline & Inlet $\rho_{s}$ & Densitometer & - & \pm 0.01 & $0.6-2.0$ \\
\hline & Outlet $\rho_{s}$ & Densitometer & - & \pm 0.01 & $0.6-2.0$ \\
\hline Data & & $\begin{array}{l}\text { Data automatic } \\
\text { recorder }\end{array}$ & Agilent 34970A & - & - \\
\hline
\end{tabular}

The packing material used was a structured PVC (polyvinyl chloride) material with dimensions of $5000 \mathrm{~mm}$ long $\times 3300 \mathrm{~mm}$ wide $\times 2900 \mathrm{~mm}$ high for counter-flow, and $1460 \mathrm{~mm}$ long $\times 970 \mathrm{~mm}$ wide $\times 1060 \mathrm{~mm}$ high for cross-flow. The counter-flow HST experiment was carried out during the 11:50-18:30 period within five days under outdoor inlet air conditions, while the cross-flow experiment was carried out during the 14:30-18:15 period.

$T_{s, o}, T_{a, o}$ and $\omega_{a, o}$ were selected for verification. Figure 7 demonstrates the difference between the simulation data and the experimental data. The $\mathrm{R}^{2}, \mathrm{r}$ and RMSE (root mean square error) were carried during the model verification. The model verification of the cross-flow model is based on the experimental data from Appendix A, and the model was also used for counter-flow verification using the data from $\mathrm{Lu}$ [29]. 


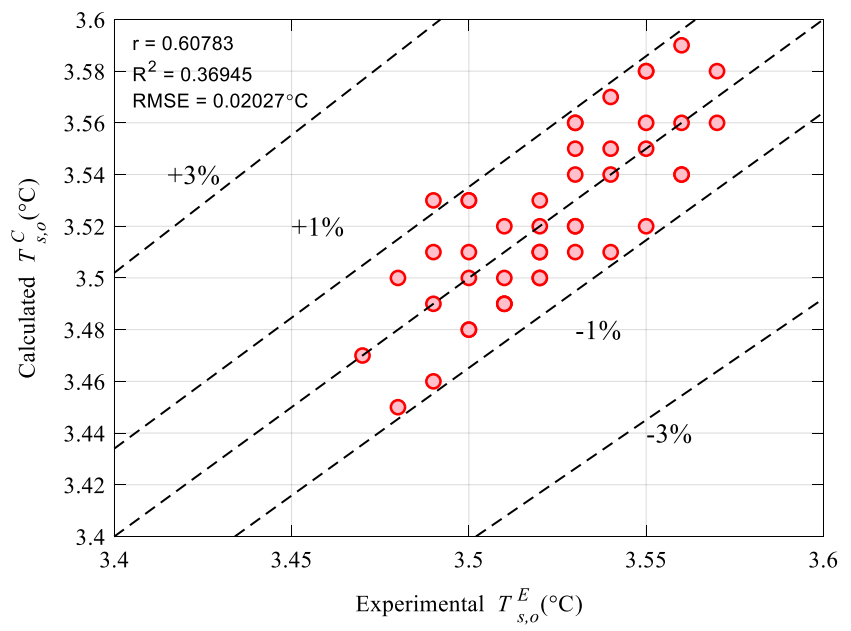

(a)

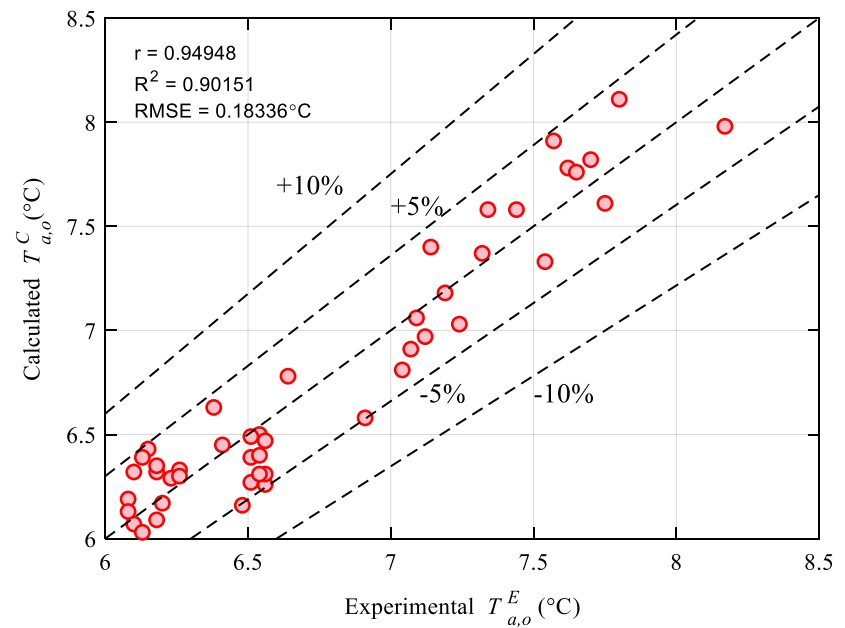

(b)

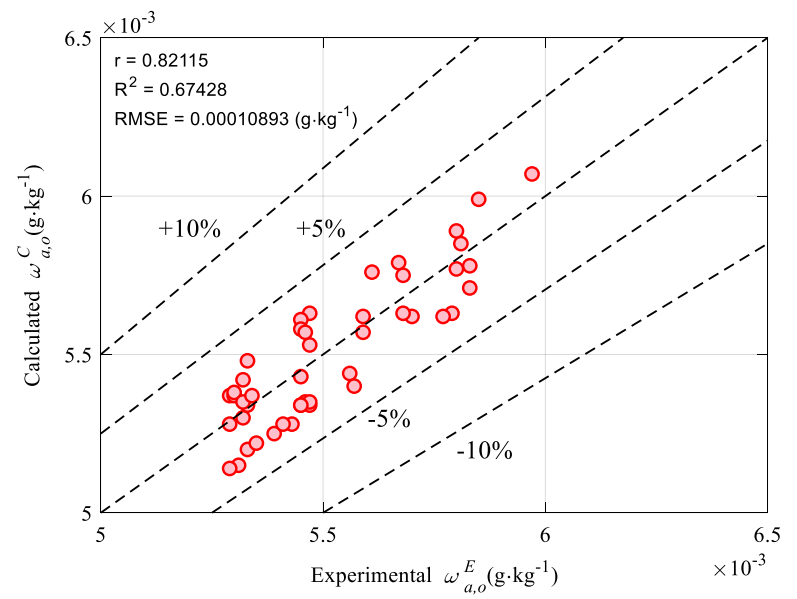

(c)

Figure 7. The experimental data vs. the simulated data of cross-flow HST: (a) outlet solution temperature; (b)outlet air temperature $T_{a, o}$; (c)outlet air humidity ratio $\omega_{a, o}$. 
The parameters used to quantify the packing material are mainly the porosity and packing space. The influence of these parameters on the thermal behaviour of the filler was discussed in Section 4.3. Different flow directions cannot directly affect these parameters, but they will cause different heat and mass transfer processes between the air and the solution inside the packing material, which indirectly affects the thermal performance of HST. Therefore, the thermal behaviour of a counter-flow HST and a cross-flow HST are different.

\section{Parametric Study}

Through the mathematical model verified in the previous section, the mass and energy transfer of HST can be predictable, to compare the thermodynamic characteristics between the cross-flow and counter-flow HST, the same inlet boundary conditions are used for the calculation.

It can be reflected in Figure 8 that the air temperature decreases as the solution temperature increases. This figure shows the distribution of air and solution temperature inside the packing material. The form of this figure is a box diagram, where the box is used to represent the parameter distribution of cross-flow at the same height, the upper and lower boundaries are the maximum and minimum values of a set of data, and the upper and lower limits of the box are a set of $1 / 4$ quantile of data. This phenomenon mainly due to the temperature difference between the air and the solution. Therefore, SHT (sensible heat transfer) occurs due to the temperature difference, and latent heat transfer (LHT) occurs simultaneously. The air temperature decreases from $6.0^{\circ} \mathrm{C}$ to $1.88^{\circ} \mathrm{C}$ with the solution temperature increases from $-3.0^{\circ} \mathrm{C}$ to $-1.126^{\circ} \mathrm{C}$. In addition, for the cross-flow HST, the air temperature decreases from $3.82^{\circ} \mathrm{C}$ to $3.09^{\circ} \mathrm{C}$ as the solution temperature increases from $-3.0^{\circ} \mathrm{C}$ to $-0.924{ }^{\circ} \mathrm{C}$. Table 4 shows the Simulation boundary conditions.

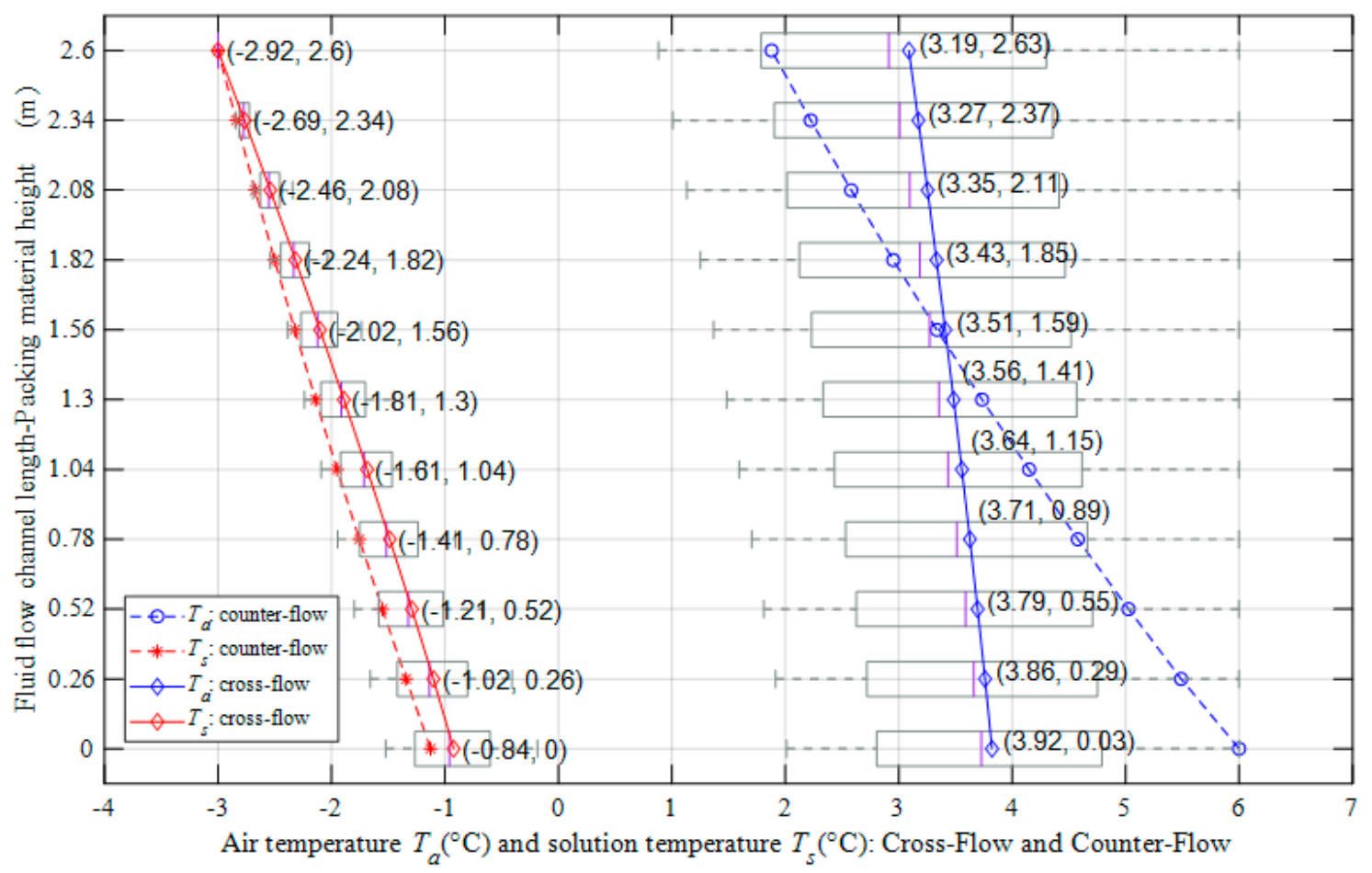

Figure 8. Variation of fluid temperature within the fluid flow channel length. 
Table 4. Simulation boundary conditions.

\begin{tabular}{cccccccc}
\hline Simulation Condition & $\mathbf{T}_{\mathbf{a}, \mathbf{i}}\left({ }^{\circ} \mathbf{C}\right)$ & $\mathbf{T}_{\mathbf{s}, \mathbf{i}}\left({ }^{\circ} \mathbf{C}\right)$ & $\mathbf{M}_{\mathbf{a}, \mathbf{i}}\left(\mathbf{k g} \cdot \mathbf{s}^{-1}\right)$ & $\mathbf{M}_{\mathbf{s , i}}\left(\mathbf{k g} \cdot \mathbf{s}^{-1}\right)$ & $\omega_{\mathbf{a}, \mathbf{i}}\left(\mathbf{k g} \cdot \mathbf{k g}^{-1}\right)$ & $\boldsymbol{D}(\mathbf{m})$ & $\beta$ \\
\hline Inlet air temperature & $0-12$ & -3 & 40 & 37.7 & 0.0045 & 0.03 & 0.98 \\
Inlet solution & 6 & $-10-+3$ & 40 & 37.7 & 0.0045 & 0.03 & 0.98 \\
temperature & & -3 & $10-80$ & 37.7 & 0.0045 & 0.03 & 0.98 \\
Inlet air mass flow rate & 6 & -3 & 40 & $10-80$ & 0.0045 & 0.03 & 0.98 \\
Inlet solution mass flow & 6 & -3 & 40 & 37.7 & $0.0026-0.0054$ & 0.03 & 0.98 \\
rate & 6 & -3 & 40 & 37.7 & 0.0045 & $0.018-0.042$ & 0.98 \\
Air inlet humidity ratio & 6 & -3 & 40 & 37.7 & 0.0045 & 0.03 & $0.54-0.98$ \\
Material packing space & 6 & 6 & & &
\end{tabular}

Figure 9a derives the temperature contour of the air in the HST. The air temperature decreases along the airflow direction (X-direction), and the air temperature changes slightly following the $\mathrm{Y}$-axis. The maximum temperature appears in the lower-left area of the $X-Y$ plane, where the temperature difference between air and solution is the minimum. However, in the upper right corner of the $X-Y$ plane, the air temperature taken lowest value here, which is caused by the maximum temperature difference between the solution and air in this area. Further, a solution temperature contour can be obtained as shown in Figure 9b. Compared with Figure 9a, the solution temperature decreases along the $\mathrm{Y}$-direction, and the air temperature changes slightly along the $\mathrm{X}$-axis. A rapid change of the solution temperature appears in the lower-left part of the X-Y plane. The temperature difference between the two fluids on the left side of the positive $\mathrm{X}$-axis region is higher, which can be the major cause of the solution temperature evolution.

The variation of the air humidity ratio is revealed in Figure 10. The air humidity ratio in both HSTs decreased along the fluid flow channel. The counter-flow air humidity ratio decreases from $4.50 \mathrm{~g} / \mathrm{kg}$ to $3.82 \mathrm{~g} / \mathrm{kg}$ and the cross-flow HST decrease is from $4.024 \mathrm{~g} / \mathrm{kg}$ to $4.157 \mathrm{~g} / \mathrm{kg}$. Part of the reason for this discovery is that a pressure difference exists between the water vapor surface and the solution surface, so consequently the moisture in the air is continuously transmitted to the solution side under the pressure difference. In addition, the LHT is spontaneously generated in the process. Moreover, the cross-flow humidity ratio decreased faster than in the counter-flow configuration. 


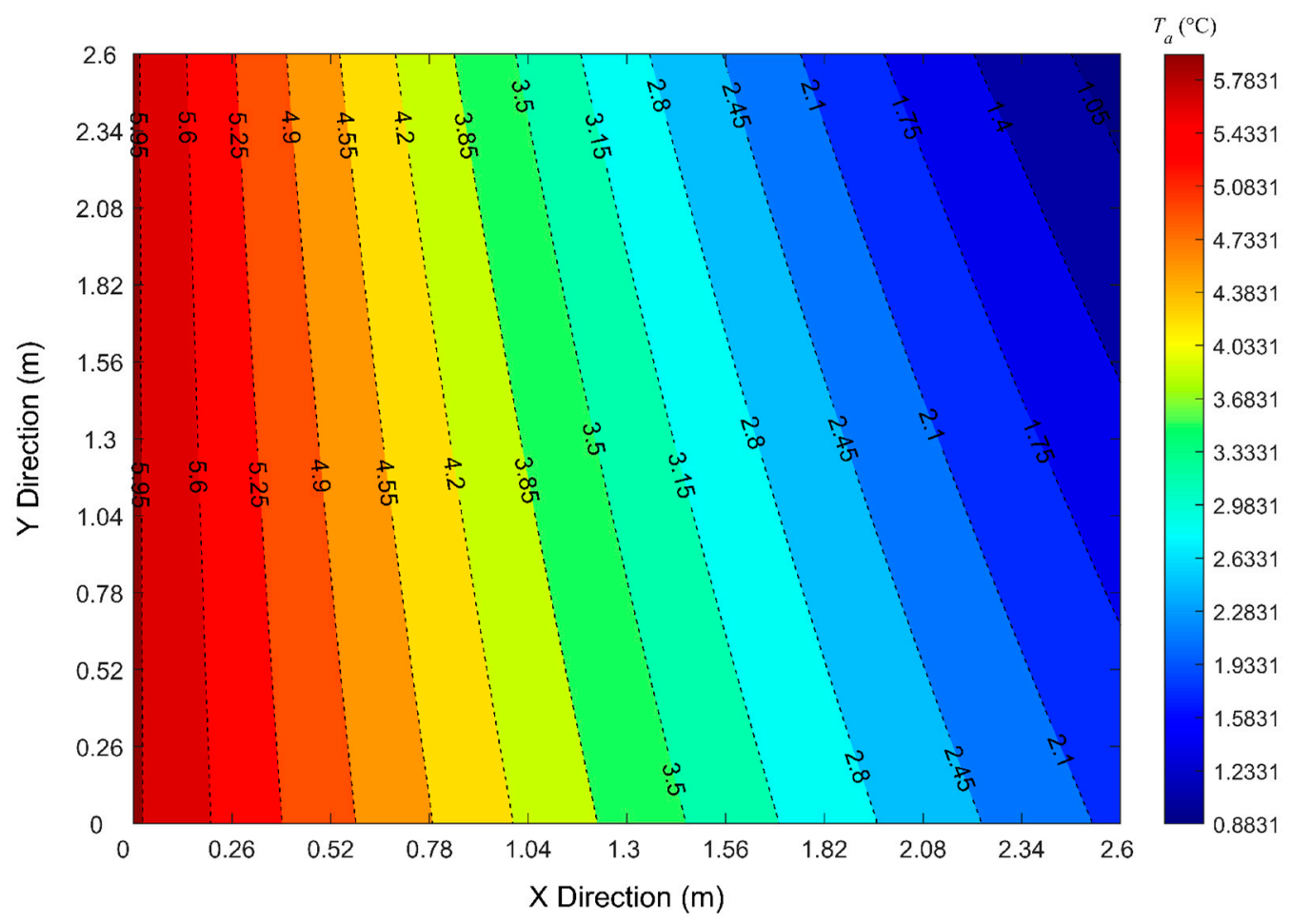

(a)

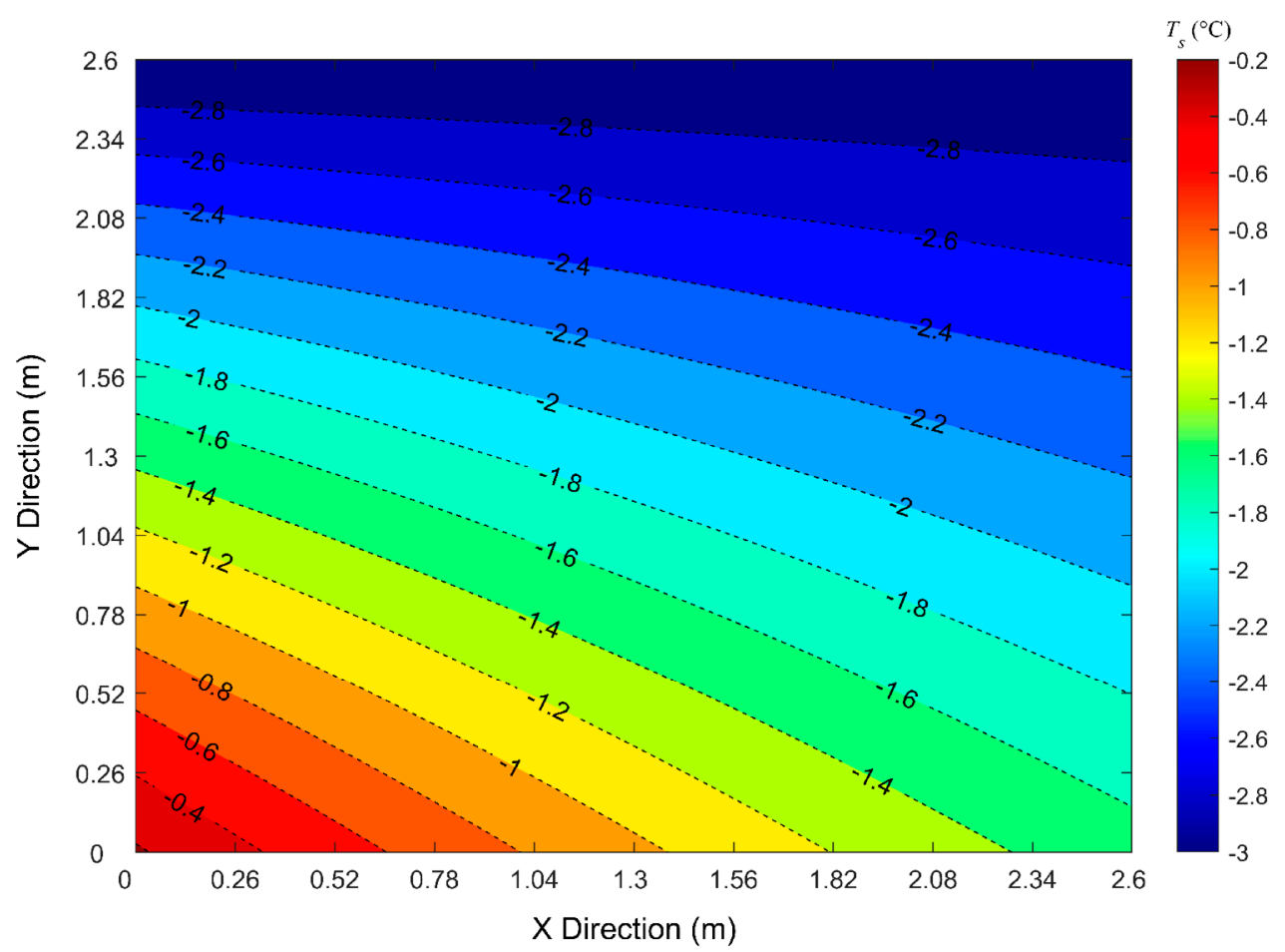

(b)

Figure 9. Solution and air temperature distributions in the packing material (cross-flow): (a) Air temperature; (b) Solution temperature. 


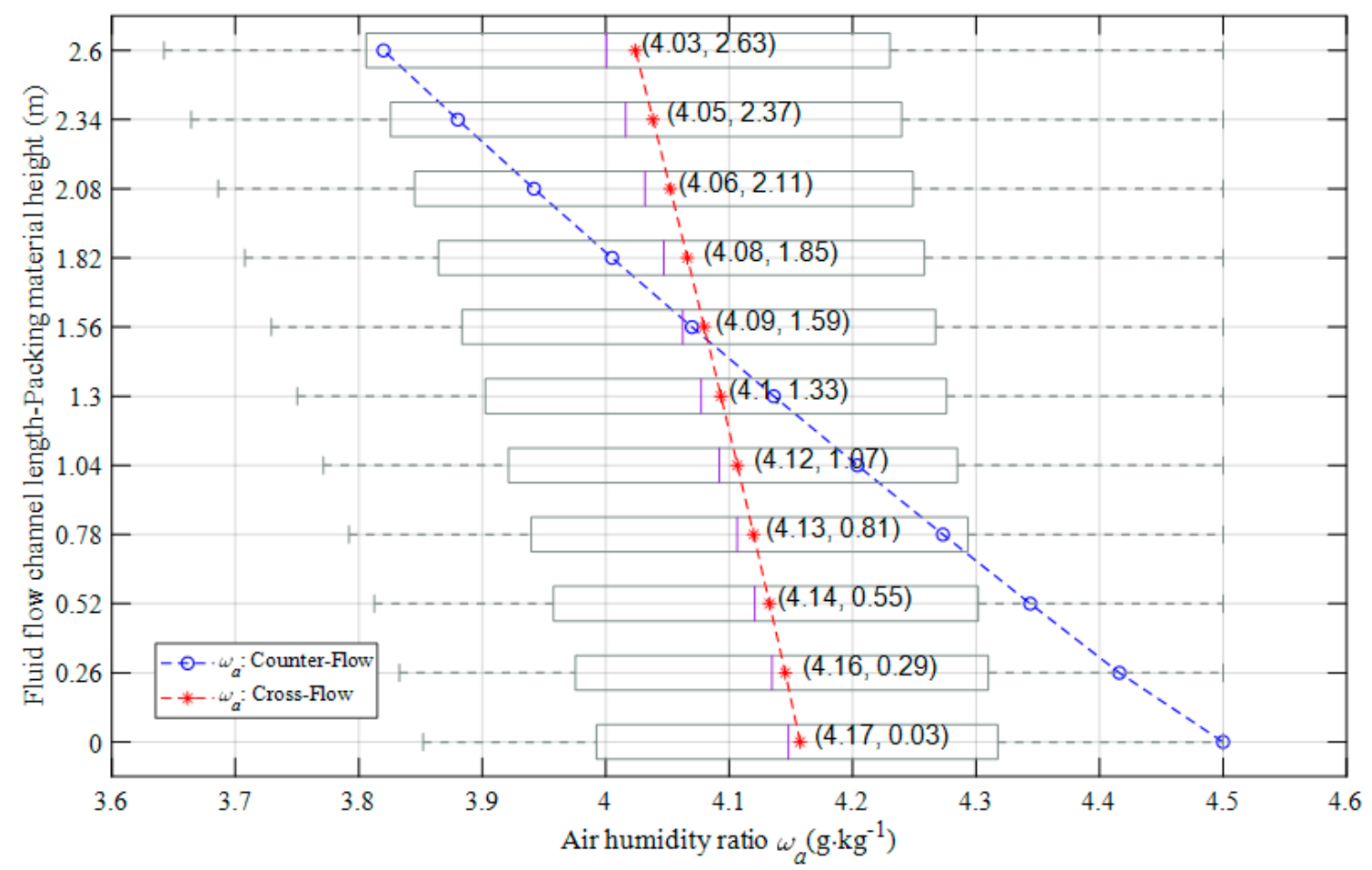

Figure 10. Variation of air humidity ratio within the fluid flow channel length.

The evolution of the solution mass flow rate is displayed in Figure 11. The solution mass flow rate varies from $37.70 \mathrm{~kg} / \mathrm{s}$ to $37.73 \mathrm{~kg} / \mathrm{s}$ for cross-flow, while the counter-flow solution mass flow increased to $37.726 \mathrm{~kg} / \mathrm{s}$. A major source for this is that the solution is diluted under the water vapor pressure difference, the solution temperature is far below the freezing point, so the solution will continuously absorb moisture from the air. However, as the freezing point approaches $0{ }^{\circ} \mathrm{C}$, the system will have a risk of freezing, so the characteristics of solution dilution should be investigated.

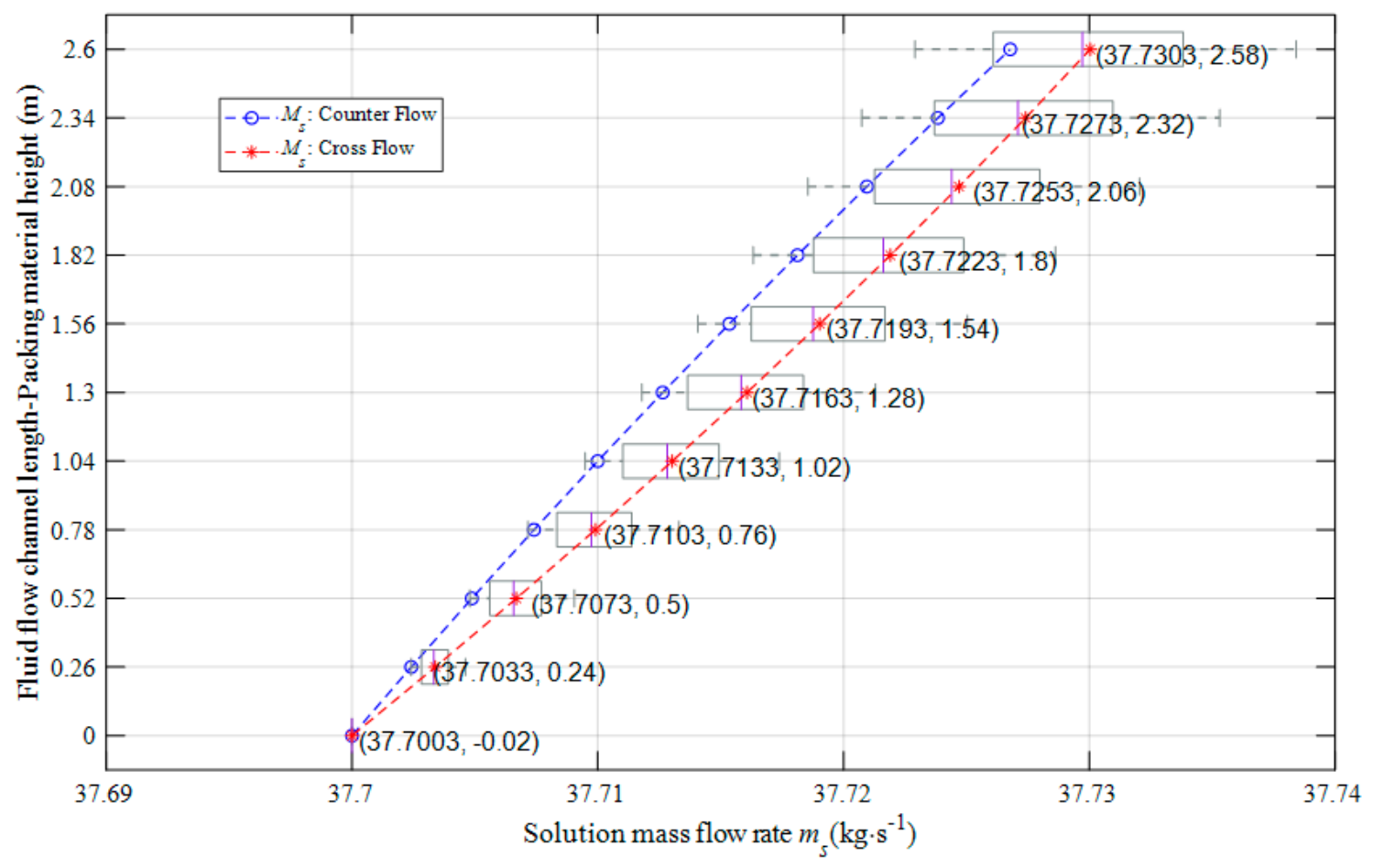

Figure 11. Profile of solution mass flow rate along the fluid flow channel length. 


\subsection{Impact of Inlet Air Parameters on Energy Transfer}

A parametric study is carried out using the above constant boundary conditions as benchmarks. In order to compare the thermodynamic properties of two HST, the SHT, LHT and $\xi$ of two HST under different air, solution and material boundary conditions will be investigated.

\subsubsection{Impact of Inlet-Air Temperature}

The energy transfer inside the HST is indicated in Figure 12. With the inlet air temperature elevates, the SHT in the HST increases, while the LHT decreases slightly and the difference of SHT between the two HSTs also increases. The counter-flow SHT increases from $73.2 \mathrm{~kW}$ to $281.2 \mathrm{~kW}$, while the SHT varies from $79.81 \mathrm{~kW}$ to $312.5 \mathrm{~kW}$ for the cross-flow setup. However, the counter-flow LHT decreases from $69.16 \mathrm{~kW}$ to $64.37 \mathrm{~kW}$ when the cross-flow varies from $78.7 \mathrm{~kW}$ to $70.45 \mathrm{~kW}$. This suggests that the air inlet temperature has a significant effect on the SHT, but has little influence on the LHT.

$\xi$ indicates the proportion of LHT caused by moisture transfer in THT. With the inlet air temperature increases, not solely counter-flow $\xi$ decreases from 0.4858 to 0.1863 significantly, but also cross-flow $\xi$ decreased from 0.4965 to 0.184 . As the air inlet temperature increases, resulting in a reduction in the air humidity ratio, the capacity of the air moisture content also decreases, following, a decrease in the LHT further triggered by a decrease in the mass transfer between the air and the solution, finally the $\xi$ decreases gradually. Accordingly, the inlet air temperature has a majority effect on $\xi$, the cross-flow $\xi$ is more sensitive to the inlet air temperature subsequently.

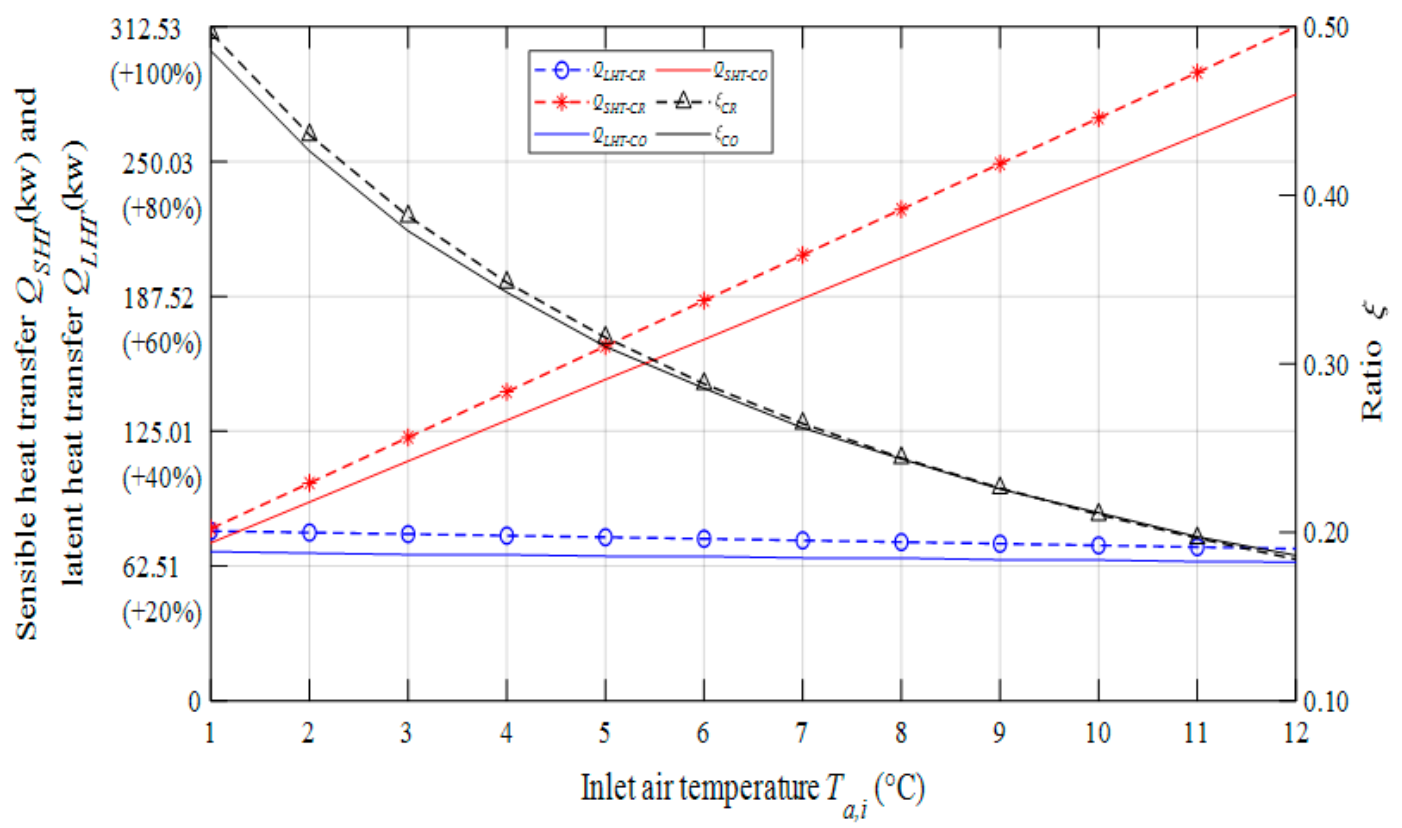

Figure 12. Influence of inlet air temperature on energy transfer characteristics.

\subsubsection{Impact of Inlet Air Humidity Ratio}

The effect of inlet air humidity ratio on energy transfer in the HST is presented in Figure 13 when the inlet air humidity ratio varies from $2.6 \mathrm{~g} / \mathrm{kg}$ to $5.4 \mathrm{~g} / \mathrm{kg}$, the LHT in the HST increases, while the SHT slightly attenuate, the difference of LHT between two HSTs also increases. It is contrary to inlet air temperature, the counter-flow SHT decreases from $170.4 \mathrm{~kW}$ to $166.6 \mathrm{~kW}$, with the cross-flow SHT varies from $190.5 \mathrm{~kW}$ to $183.2 \mathrm{~kW}$. Furthermore, the counter-flow LHT increases quickly from $-8.858 \mathrm{~kW}$ to $102.5 \mathrm{~kW}$ when cross-flow varies from $-12 \mathrm{~kW}$ to $116.3 \mathrm{~kW}$, in contrast to the inlet air temperature, the inlet air humidity ratio causes a pivotal contribution to the LHT but has little amelioration on the SHT. 


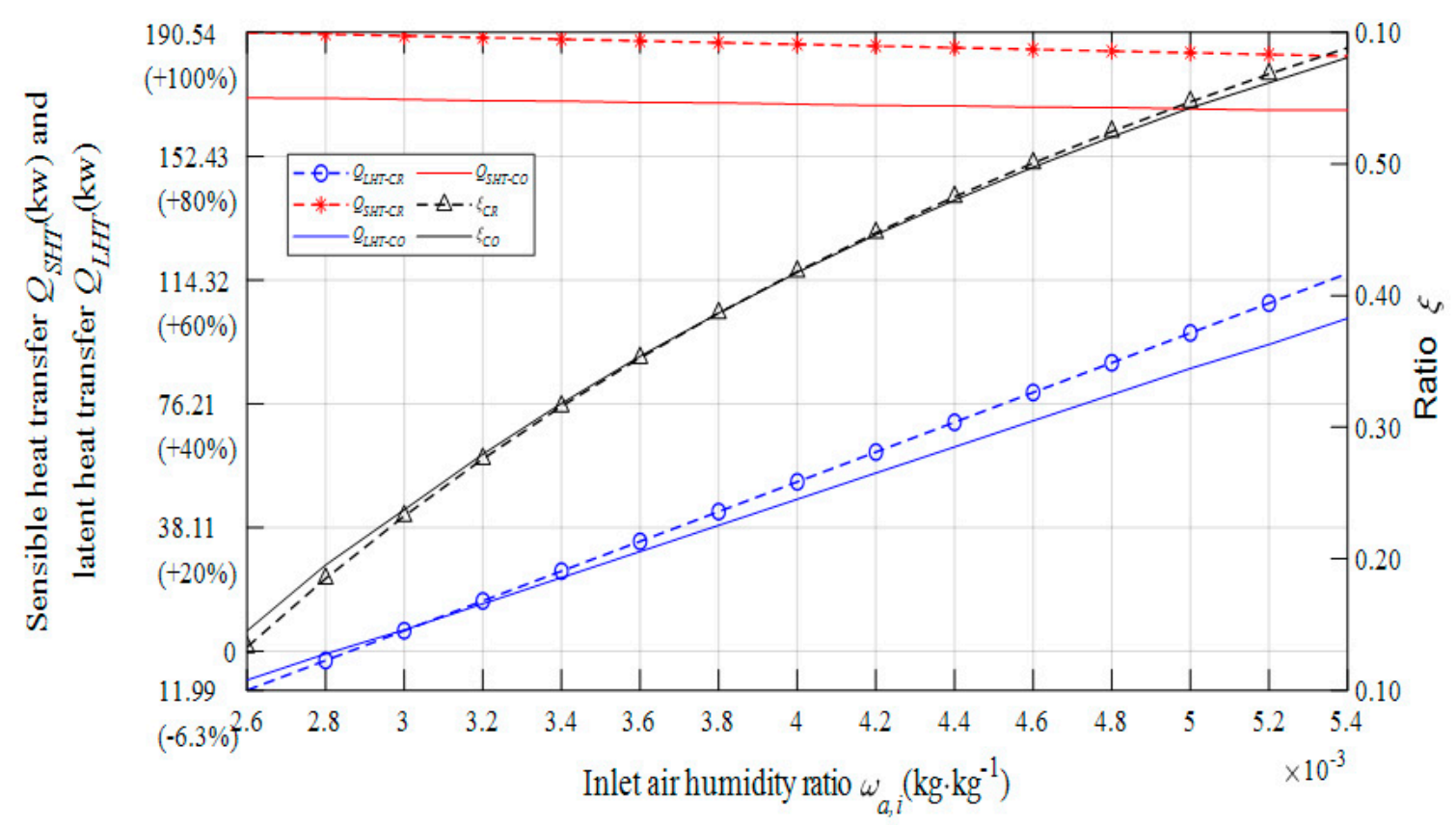

Figure 13. Influence of inlet air humidity ratio on energy transfer characteristics.

It is distinct from the $\xi$ of air inlet temperature, the counter-flow $\xi$ rises from -0.055 to 0.381 along with the cross-flow $\xi$ increases from -0.067 to 0.389 . The LHT between the fluids enhanced as the inlet air humidity ratio increased, However, the increase in air humidity doesn't drive the air temperature increases. In other words, the temperature difference is still constant, thus the SHT remains almost unchanged and even a decline is obtained. Nevertheless, the water vapor partial pressure highly increased with the air humidity ratio amplified, then the increase of LHT results in an $\xi$ increment, especially for the cross-flow HST. Hence, the inlet air humidity ratio has a significant influence on $\xi$. In spite of the LHT increase, the solution is also diluted, therefore, the HST system is at risk of freezing.

\subsubsection{Impact of Inlet Air Mass Flow Rate}

With the inlet air mass flow rate rises, both SHT and LHT increase, the difference between SHT and HST among the two HSTs also increased, which is shown in Figure 14. The counter-flow SHT increases from $68.12 \mathrm{~kW}$ to $244.1 \mathrm{~kW}$, as well as the cross-flow SHT, which varies from $73 \mathrm{~kW}$ to $271 \mathrm{~kW}$. Besides, the counter-flow LHT increases from $27.75 \mathrm{~kW}$ to $87.54 \mathrm{~kW}$ when the cross-flow varies from $31.64 \mathrm{~kW}$ to $106.2 \mathrm{~kW}$. This conveys that the air inlet mass flow rate leads to a functional increase in both SHT and LHT. By contrast, the counter-flow $\xi$ decreased from 0.287 to 0.265 with the cross-flow $\xi$ reduced from 0.302 to 0.282 .

Different from inlet air temperature and humidity ratio, there is no direct effect on the air enthalpy, on the contrary, the heat and mass transfer coefficients are indirectly changed by the air mass flow rate, which can enhance the SHT and LHT, owing to the SHT, which increases much more than LHT, so $\xi$ decreases, particularly in a counter-flow configuration. Importantly, the energy transfer times were reduced even though the energy transfer coefficients were strengthened, as a consequence, decreases in the increase rates of SHT and HST were obtained. 


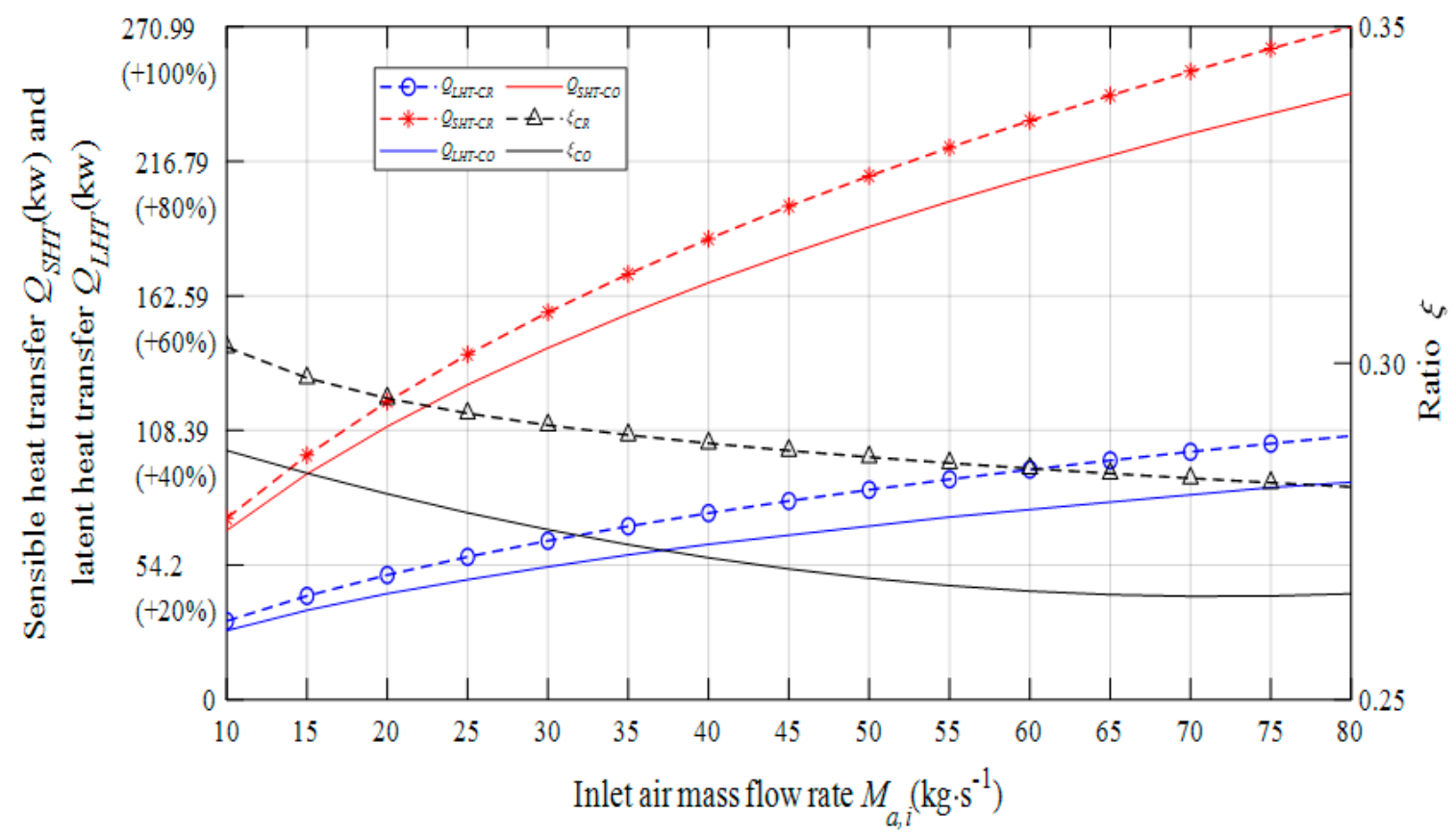

Figure 14. Influence of air inlet mass flow rate on energy transfer characteristics.

\subsection{Impact of Inlet Solution Parameters on Energy Transfer}

\subsubsection{Impact of Inlet Solution Temperature}

The variation of SHT and LHT with solution inlet temperature varies is observed in Figure 15. The counter-flow SHT decreases from $299 \mathrm{~kW}$ to $56.26 \mathrm{~kW}$ with the cross-flow SHT varies from $330.3 \mathrm{~kW}$ to $62.79 \mathrm{~kW}$. Besides, the counter-flow LHT decreases from $105.4 \mathrm{~kW}$ to $7.96 \mathrm{~kW}$ when the cross-flow varies from $127.6 \mathrm{~kW}$ to $9.29 \mathrm{~kW}$. The results have shown that the solution inlet temperature has greatly decreased the ability of SHT and LHT.

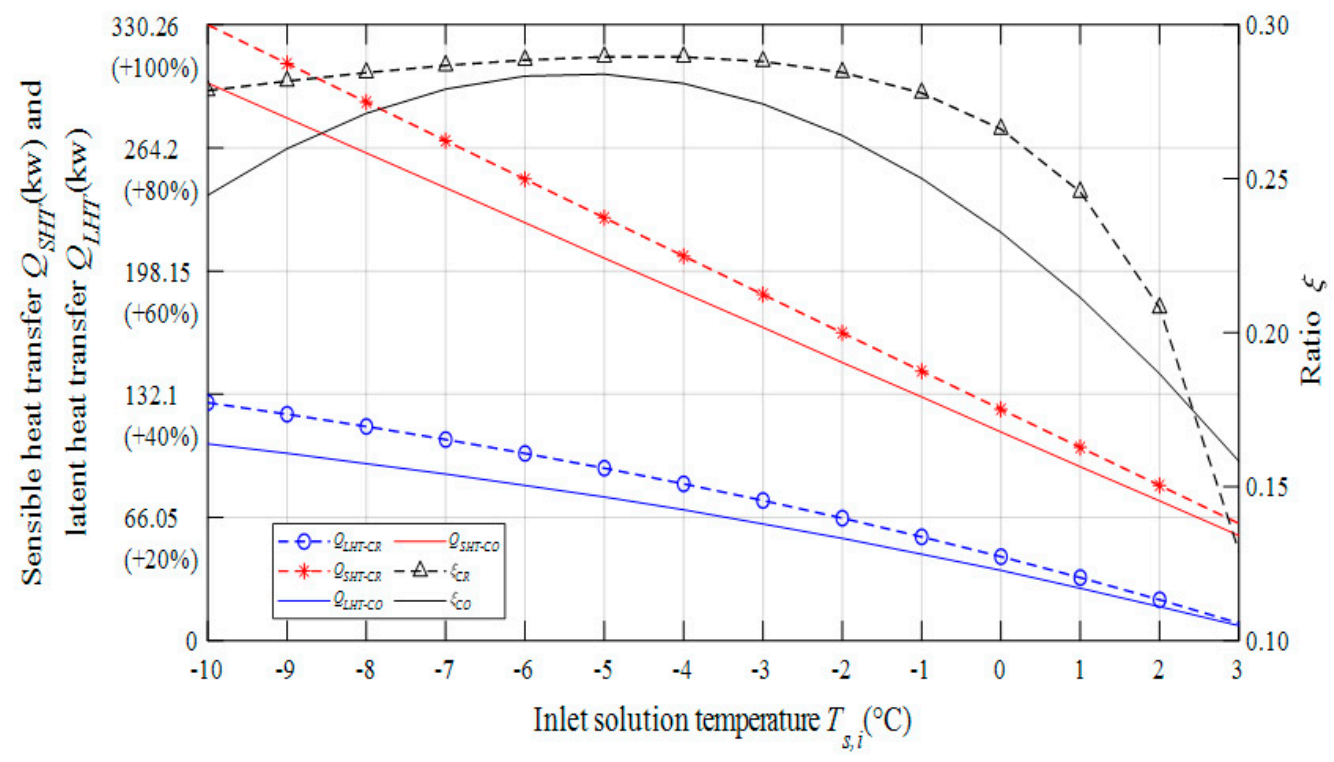

Figure 15. Influence of solution inlet temperature on energy transfer characteristics.

As the inlet solution temperature increases, $\xi$ increases first, then decreases gradually. A transition temperature occurs at $-5{ }^{\circ} \mathrm{C}, \xi$ is 0.284 and 0.289 , especially for counter-flow and cross-flow. Additionally, with the increase in solution temperature, LHT decreases rapidly. Although it can 
weaken the solution dilution, conversely, the energy transfer was reduced. As a result, the solution inlet temperature should be selected according to the HST system operating conditions.

\subsubsection{Impact of Inlet Solution Mass Flow Rate}

It was previously found that both SHT and LHT can strengthen significantly with the air mass flow rate is increased. The influence of the solution inlet mass flow rate on energy transfer characteristics is shown as Figure 16. The counter-flow SHT increases from $129.8 \mathrm{~kW}$ to $178.1 \mathrm{~kW}$ with the cross-flow SHT varies from $135.2 \mathrm{~kW}$ to $200.2 \mathrm{~kW}$. Then, the counter-flow LHT increases only from $45.05 \mathrm{~kW}$ to $66.26 \mathrm{~kW}$ and likewise cross-flow varies from $50.18 \mathrm{~kW}$ to $80.61 \mathrm{~kW}$. The results have revealed that the solution mass flow rate has little influence on SHT and LHT.

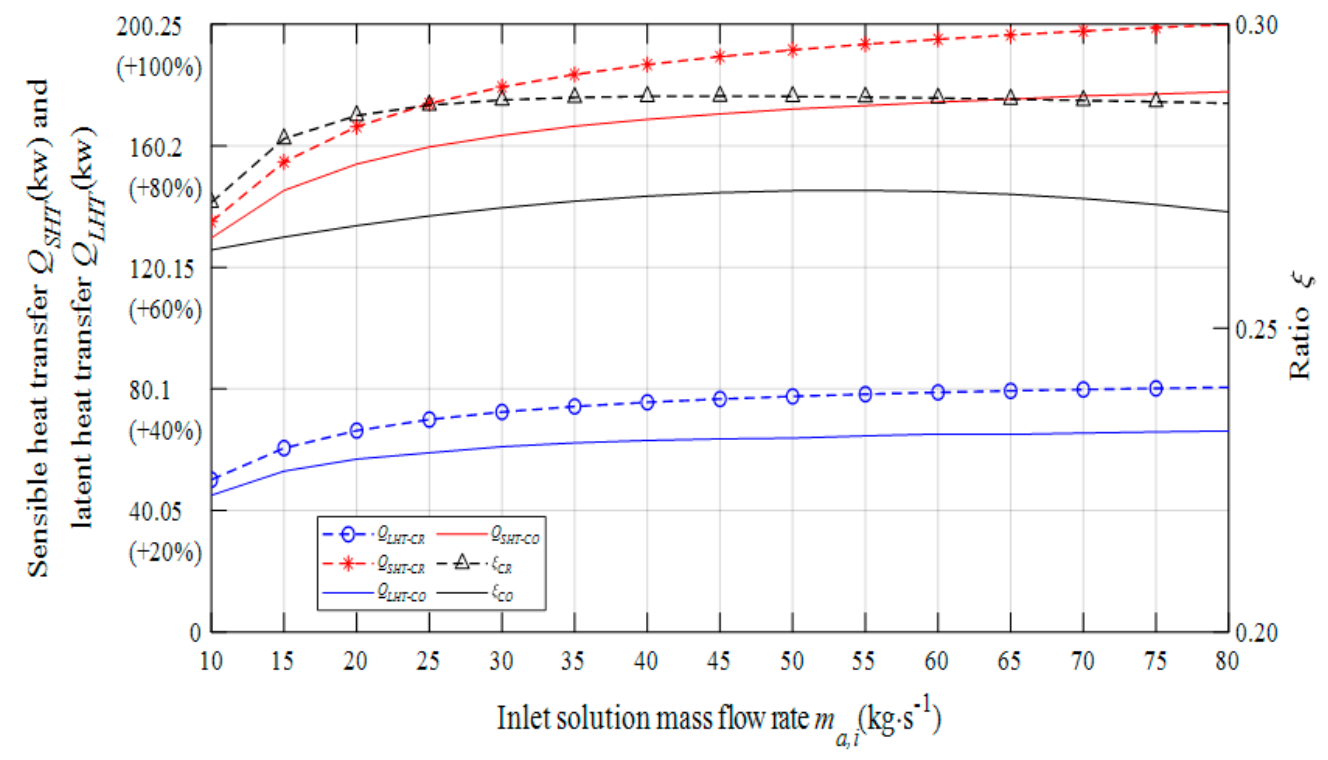

Figure 16. Influence of solution inlet mass flow rate on energy transfer characteristics.

When the inlet mass flow reaches $25 \mathrm{~kg} / \mathrm{s}$, the value of $\xi$ almost remains constant. As a matter of fact, both SHT and LHT stay at a high value. In addition, a higher solution mass flow rate brings about a slower increment of energy transfer. Therefore, the solution mass flow rate should be selected precisely.

\subsection{Impact of Material Parameters on Energy Transfer}

\subsubsection{Impact of Material Packing Space}

The influence of material packing space with SHT and LHT is presented in Figure 17. The counter-flow SHT decreases from $257 \mathrm{~kW}$ to $117 \mathrm{~kW}$ with the cross-flow SHT varies from $264.4 \mathrm{~kW}$ to $133.9 \mathrm{~kW}$. Moreover, the counter-flow LHT decreases from $102.8 \mathrm{~kW}$ to $42.39 \mathrm{~kW}$ as the cross-flow varies from $112.8 \mathrm{~kW}$ to $52.98 \mathrm{~kW}$. Furthermore, it is also seen that the value of $\xi$ keeps decreasing slightly with the increase of material packing space. The cross-flow $\xi$ decreases from 0.2991 to 0.2835 and from 0.2856 to 0.2666 for counter-flow. The above results indicate that the solution material packing space should be as small as possible under demand. 


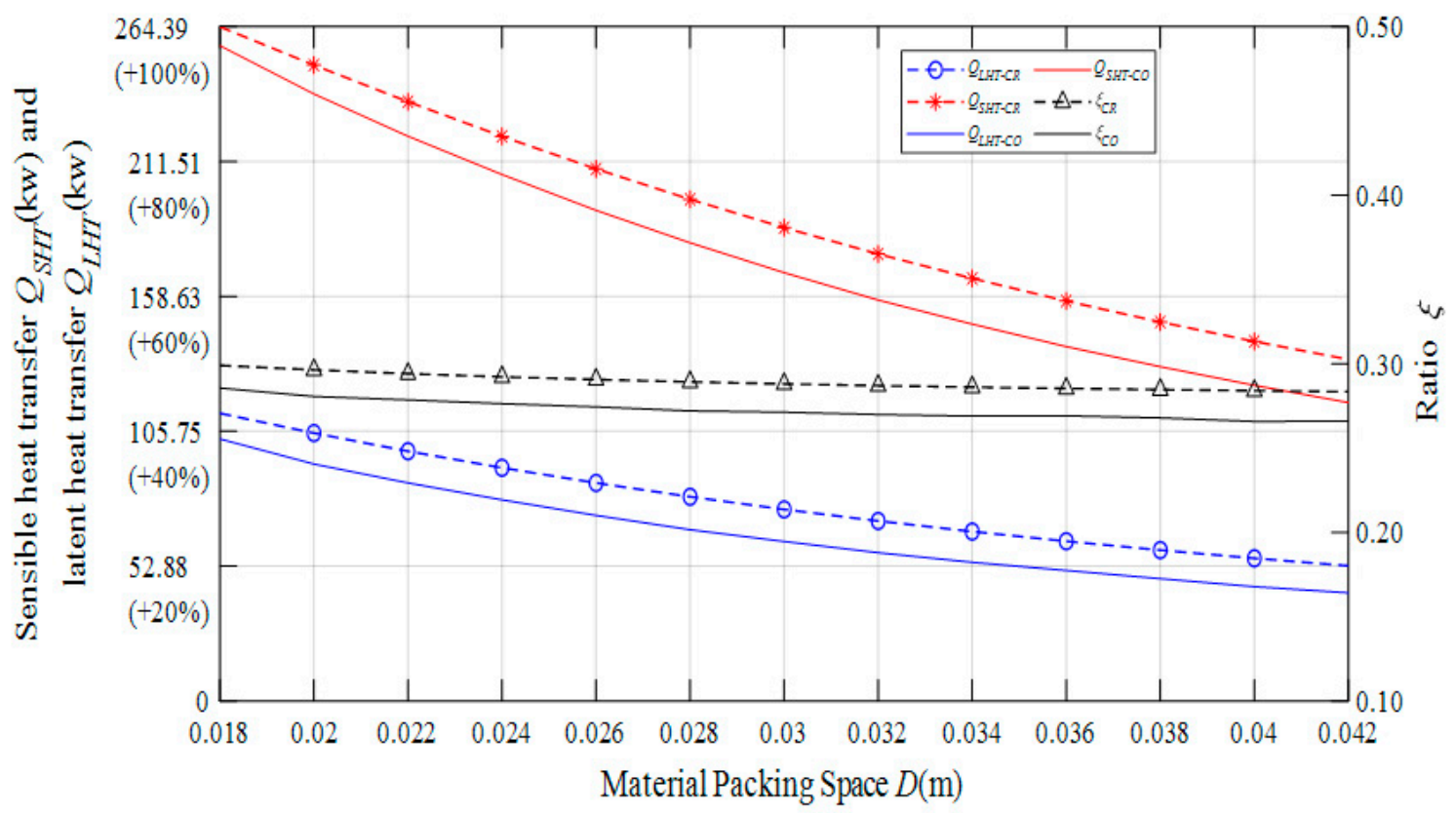

Figure 17. Influence of material packing space on energy transfer characteristics.

\subsubsection{Impact of Material Porosity}

The influence of material porosity with SHT and LHT is proposed in Figure 18. The counter-flow SHT increases from $109.4 \mathrm{~kW}$ to $168 \mathrm{~kW}$ with the cross-flow SHT varies from $125.8 \mathrm{~kW}$ to $185.6 \mathrm{~kW}$. Moreover, the counter-flow LHT increases from $39.6 \mathrm{~kW}$ to $62.52 \mathrm{~kW}$ when the cross-flow varies from $49.63 \mathrm{~kW}$ to $75.1 \mathrm{~kW}$. Furthermore, it is also seen that the value of $\xi$ keeps increasing slightly with the increase of material porosity. The counter-flow $\xi$ increases from 0.265 to 0.272 and from 0.282 to 0.288 for cross-flow.

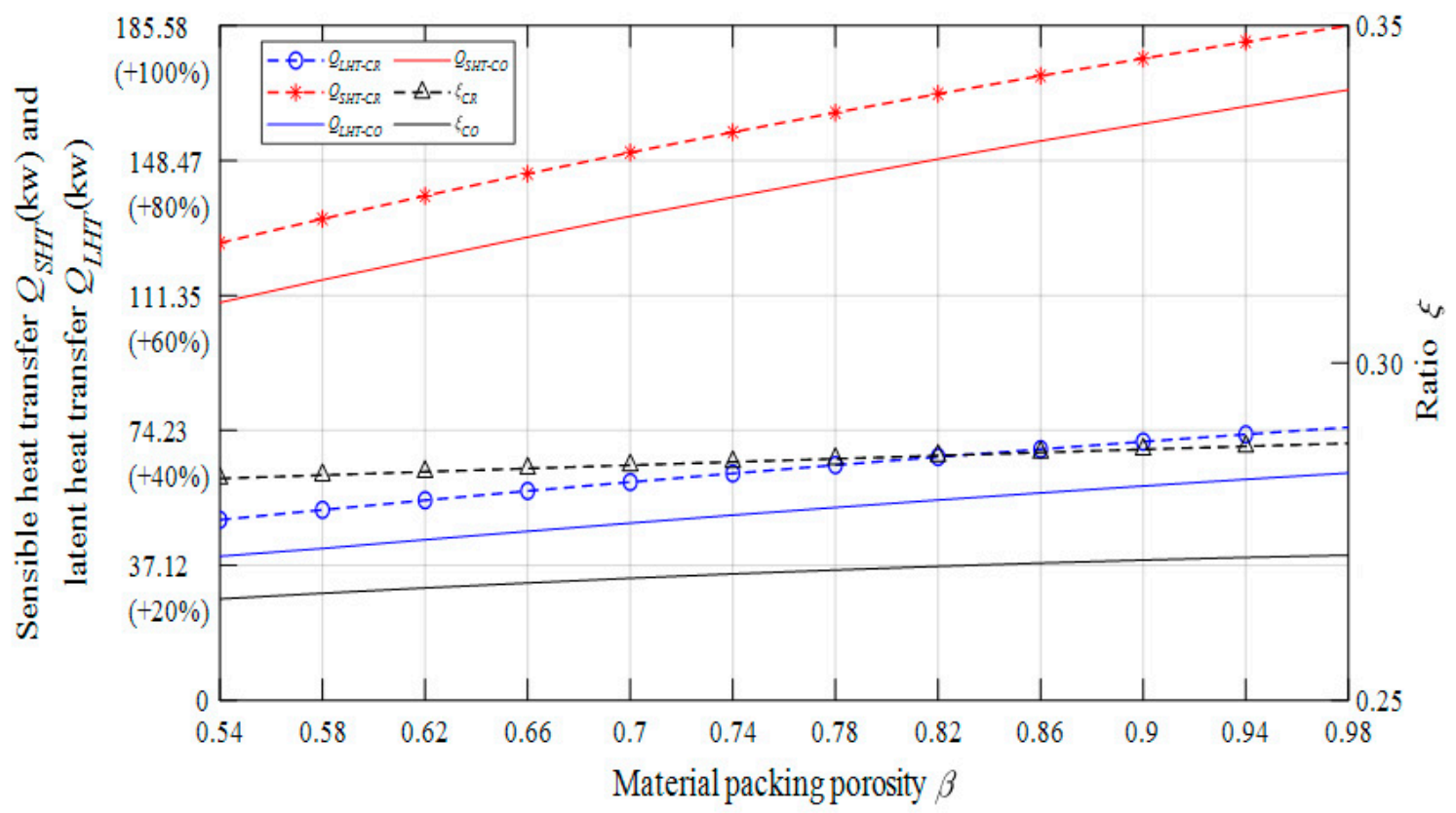

Figure 18. Influence of material packing porosity on energy transfer characteristics.

\subsection{Investigation on Solution Dilution Characteristics}

The above parametric study about air, solution and packing material revealed the effect on energy transfer, then the previous research has specifically shown a strong link between mass flow as well as 
humidity ratio and LHT. Nevertheless, LHT derives from moisture transfer between air and solution which may cause the solution freezing point to raise and even the HST system to break down. Thus, there are further reasons to investigate solution dilution characteristics thoroughly.

When the air relative humidity varies from $10 \%$ to $100 \%$, the direction of moisture transfer also changes, which as shown in Figure 19. First, when the air relative humidity within $10-49 \%$, the solution in both cross-flow and counter-flow HST is dehumidified, while, the air is humidified. Second, when the air relative humidity is between $49-60 \%$, the direction of moisture transfer will be reversed in counter-flow HST, in other words, the solution will be diluted and dehumidified for counter-flow and cross-flow, respectively. Third, when the air relative humidity higher than $60 \%$, solution in both cross-flow and counter-flow HST are diluted, while the air is dehumidified. Therefore, it can be seen from the previous research that although cross-flow HST has a better energy transfer coefficient than the counter-flow, the counter-flow HST can operate under $49-60 \%$ air relative humidity, while the cross-flow HST can only operate above $60 \%$ air relative humidity in winter.

Further analysis needs to be performed on the moisture transfer of internal HST under $50 \%$ air relative humidity conditions, in order to analyze the reasons why the mass transfer direction changed. The variation of air humidity ratio in the air flow $\omega_{a}$ and air humidity ratio at the air-solution interface $\omega_{s}$ along the fluid flow channel length under $50 \%$ air relative humidity are shown in Figure 20. As the air flows upward, the difference in humidity ratio between the solution boundary layer and the air decreases below $0.78 \mathrm{~m}$ height, for counter-current HST, meanwhile, the solution humidity ratio is always higher than the air humidity ratio, this suggests that the air absorbs moisture from the solution. Conversely, the solution absorbs moisture from the air above the $0.78 \mathrm{~m}$. For cross-flow, there is a transition zone, which lies between $0.26-1.56 \mathrm{~m}$. Ultimately, the solution absorbed moisture from the air for whole packing material, and the moisture transfer rate is $0.8933 \mathrm{~g} / \mathrm{s}$ and $-11.01 \mathrm{~g} / \mathrm{s}$ for counter-flow and cross-flow respectively. It can be concluded that moisture transfer occurs in different directions at different heights, the transition surface is located in the $0.78 \mathrm{~m}$ for counter-flow and $0.26-1.56 \mathrm{~m}$ for cross-flow of the material packing height under $50 \%$ air relative humidity.

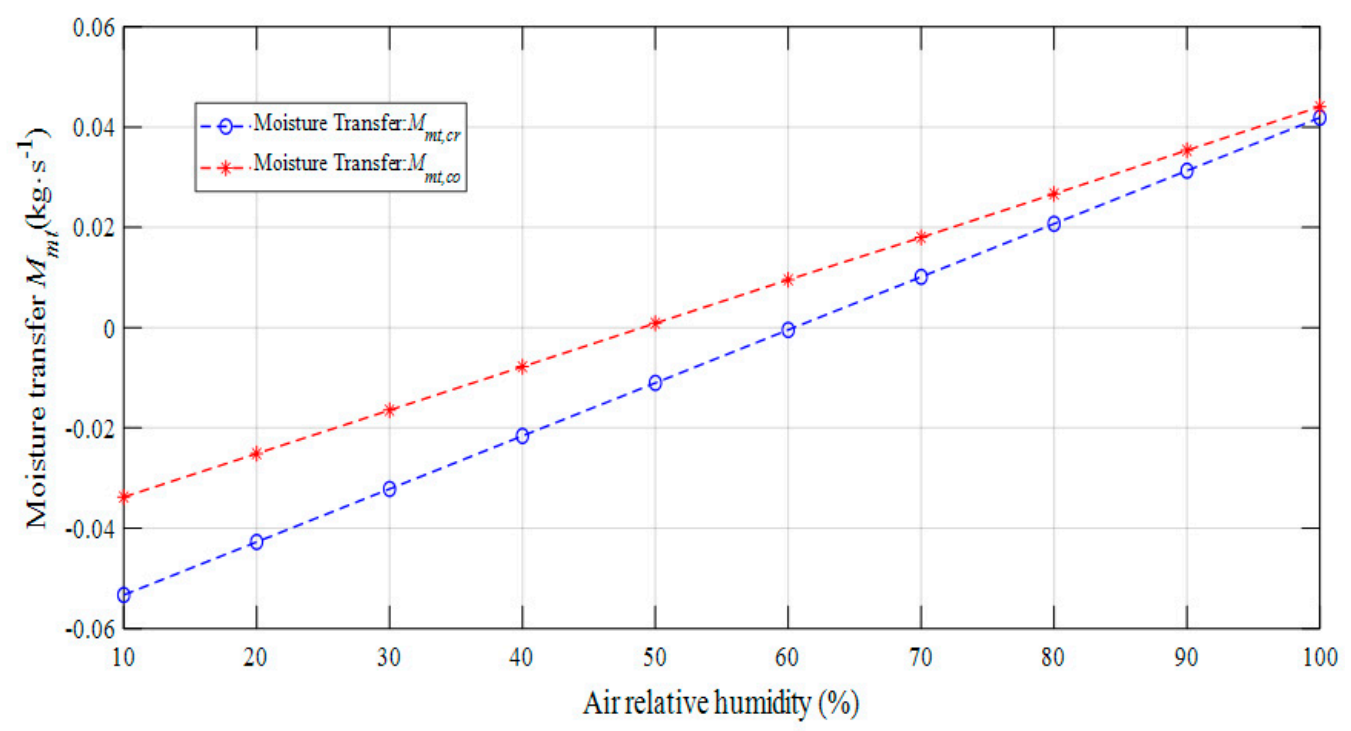

Figure 19. Influence of the relative humidity on moisture transfer. 


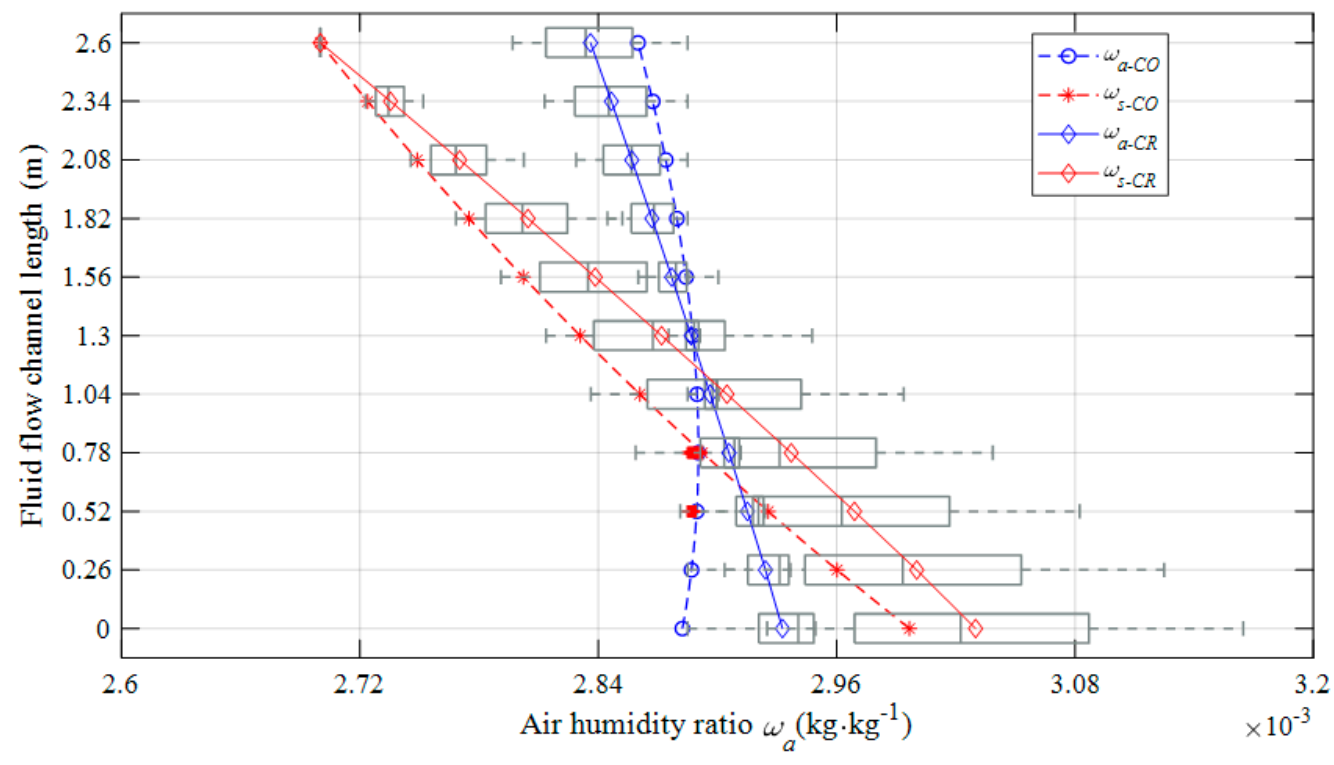

Figure 20. Variation of $\omega_{a}$ and $\omega_{s}$ along the fluid flow channel length-RH $=50 \%$.

\section{Conclusions}

This paper numerically investigated the energy transfer characteristics in the HST with packing material. A mathematical model validated by experiments was developed for predicting the HST, considering counter-flow and cross-flow simultaneously. The main conclusions are as follows:

- A higher air inlet temperature can improve the energy transfer performance of the HST. The above studies illustrated that as the inlet air temperature increases, the SHT increases, while the LHT and $\xi$ are decreased, especially for cross-flow. Besides, the air inlet temperature leads to a significant effect on the SHT and $\xi$, but has little influence on the LHT. Conversely, when the air humidity ratio increases, the LHT increases, while the SHT and $\xi$ decrease. Moreover, the inlet air humidity ratio causes a pivotal contribution to the LHT and $\xi$ but has little amelioration effect on the SHT. However, the air inlet mass flow rate leads to a functional increase in both SHT and LHT.

- The results have shown that inlet solution temperature greatly decreases the ability of SHT and LHT, and both SHT and LHT decrease when the solution inlet temperature increases. Further, as the inlet solution temperature increases, $\xi$ increases first, then decreases gradually, but a transition point occurs in the solution at $-5^{\circ} \mathrm{C}$. In addition, the solution mass flow rate has little influence on SHT and LHT.

- The variation of packing space is opposite to that of packing porosity. The SHT and the LHT are simultaneously reduced as the packing space increases. Meanwhile, the SHT and the LHT increase as the packing porosity increases. The influence of the packing spacing on the energy transfer is higher than that of the packing porosity. Additionally, counter-flow HST is less affected than cross-flow. The results have found that solution material packing space should be as small as possible under demand conditions.

- The mass transfer amount and direction vary with the air relative humidity. The transition air relative humidity of the mass transfer direction is $50 \%$ and $60 \%$, respectively, for the counter-flow and cross-flow HST. It also can be concluded that moisture transfer occurs in different directions at different heights, the counter-flow transition surface is located at $0.78 \mathrm{~m}$, while the cross-flow transition area lies between $0.26-1.56 \mathrm{~m}$ of the material packing height under $50 \%$ air relative humidity. 
Author Contributions: Conceptualization, Y.L. (Yifei Lv); methodology, Y.L. (Yifei Lv); software, L.Y. (Lulu Yang); validation, L.Y. (Linlin Yuan); formal analysis, Y.L. (Yongcai Li) and L.X.; investigation, J.L.; resources, J.L.; data curation, L.X.; writing —original draft preparation, Y.L. (Yifei Lv); writing-review and editing, Y.L. (Yifei Lv); visualization, Y.L. (Yongcai Li); supervision, J.L.; project administration, J.L.; funding acquisition, J.L. All authors have read and agreed to the published version of the manuscript.

Funding: This work was supported by the National Science Foundation of China [No. 51478058 and No. 51708054].

Conflicts of Interest: The authors declare no conflict of interest.

\section{Nomenclature}

A

$C_{p}$

$\mathrm{C}_{p, \mathrm{H}_{2} \mathrm{O}}$

$D$

$D_{a}$

$d_{s}$

W

H

$H_{i}$

$H_{0}$

$H_{S}$

$H^{i j, s}$

$\mathrm{Ha}$

$H^{i, j, a}$

$h_{c}$

$h_{m}$

$K_{a}$

K

Le

$L$

$m_{a}$

$m^{i, j, a}$

$M_{a i}$

$M_{m t}$

$m_{s}$

$m^{i, j, s}$

$M_{s, i}$

N

$N_{T U} U_{m}$

$P_{\text {atm }}$

$P_{c}$

$P_{f}$

Pr

$r$

Re

Sc

Sh

$Q_{S H T}$

$Q_{S H T-C r}$

QSHT-Co

$Q_{L H T}$

$Q_{\text {LHT-Cr }}$

$Q_{\text {LHT-Co }}$

$T_{a}$

$T_{a, i}$

Packing material heat and mass transfer surface, $\mathrm{m}^{2}$

Specific heat of air, $\mathrm{kJ} \cdot \mathrm{kg}^{-1} \cdot \mathrm{K}^{-1}$

Specific heat of water, $\mathrm{kJ} \cdot \mathrm{kg}^{-1} \cdot \mathrm{K}^{-1}$

Material packing space, (m)

Diffusion coefficient of water vapor in the air, $\mathrm{m}^{2} \cdot \mathrm{s}^{-1}$

The equivalent diameter of the packing material, $\mathrm{m}$

Width of the packing material, $\mathrm{m}$

Enthalpy, $\mathrm{kJ} \cdot \mathrm{kg}^{-1}$

The sum of the enthalpy entering the control volume, $\mathrm{kJ} \cdot \mathrm{kg}^{-1}$

The sum of the enthalpy flowing out of the control volume, $\mathrm{kJ} \cdot \mathrm{kg}^{-1}$

Solution enthalpy, $\mathrm{kJ} \cdot \mathrm{kg}^{-1}$

Solution control volume enthalpy in row $i$ and column $j, \mathrm{~kJ}^{\mathrm{kg}} \mathrm{kg}^{-1}$

Air enthalpy, $\mathrm{k} \cdot \mathrm{kg}^{-1}$

Air control volume enthalpy in row $i$ and column $j, \mathrm{~kJ}^{-\mathrm{kg}^{-1}}$

Heat transfer coefficient, $\mathrm{W} \cdot \mathrm{m}^{-2} \cdot \mathrm{K}^{-1}$

Mass transfer coefficient, $\mathrm{W} \cdot \mathrm{m}^{-2} \cdot \mathrm{K}^{-1}$

The thermal conductivity of air, $\mathrm{W} \cdot \mathrm{m}^{-1} \cdot \mathrm{C}^{-1}$

The grid numbers in the y directions

Lewis number

Length of the packing material, $\mathrm{m}$

Air mass flow rate, $\mathrm{kg} \cdot \mathrm{s}^{-1}$

Air control volume mass flow rate in row $i$ and column $j, \mathrm{~kg} \cdot \mathrm{s}^{-1}$

Inlet air mass flow rate, $\mathrm{kg} \cdot \mathrm{s}^{-1}$

Moisture transfer, $\mathrm{g} \cdot \mathrm{s}^{-1}$

Solution mass flow rate, $\mathrm{kg} \cdot \mathrm{s}^{-1}$

Solution control volume mass flow rate in row $i$ and column $j, \mathrm{~kg} \cdot \mathrm{s}^{-1}$

Inlet solution mass flow rate, $\mathrm{kg} \cdot \mathrm{s}^{-1}$

The grid numbers in the $x$-directions

Mass transfer unit number

Local standard atmospheric pressure, $\mathrm{kPa}$

Critical pressure of water, $\mathrm{kPa}$

Solution vapor partial pressure on the boundary layer of the solution, $\mathrm{kPa}$

Prandtl number

Water latent heat of condensation at $0^{\circ} \mathrm{C}, \mathrm{kJ} \cdot \mathrm{kg}^{-1} \cdot \mathrm{k}^{-1}$

Reynolds number

Schmidt number

Sherwood number

Sensible heat transfer, $\mathrm{kW}$

Cross-flow sensible heat transfer, $\mathrm{kW}$

Counter-flow sensible heat transfer, $\mathrm{kW}$

Latent heat transfer, $\mathrm{kW}$

Cross-flow latent heat transfer, $\mathrm{kW}$

Counter-flow latent heat transfer, $\mathrm{kW}$

Air temperature, ${ }^{\circ} \mathrm{C}$

Inlet air temperature, ${ }^{\circ} \mathrm{C}$ 
$T_{c} \quad$ The critical temperature of the water, $\mathrm{K}$

$T_{S} \quad$ solution temperature, ${ }^{\circ} \mathrm{C}$

$T_{S, O-C r} \quad$ Counter-flow outlet solution temperature, ${ }^{\circ} \mathrm{C}$

$T_{s, O-C o} \quad$ Cross-flow outlet solution temperature, ${ }^{\circ} \mathrm{C}$

$T_{s, i} \quad$ Inlet solution temperature, ${ }^{\circ} \mathrm{C}$

$T_{s, 0} \quad$ Outlet solution temperature, ${ }^{\circ} \mathrm{C}$

$B \quad$ Height of the packing material, $m$

$\omega_{S} \quad$ Solution boundary layer humidity ratio, $\mathrm{kg} \cdot \mathrm{kg}^{-1}$

$\omega_{s, \text { Co }} \quad$ Counter-flow solution boundary layer humidity ratio, $\mathrm{kg} \cdot \mathrm{kg}^{-1}$

$\omega_{s, C r} \quad$ Cross-flow solution boundary layer humidity ratio, $\mathrm{kg} \cdot \mathrm{kg}^{-1}$

$\omega_{s}^{i, j} \quad$ Solution boundary layer control volume humidity ratio in row $i$ and column $j, \mathrm{~kg} \cdot \mathrm{kg}^{-1}$

$\omega_{a} \quad$ Air humidity ratio, $\mathrm{kg} \cdot \mathrm{kg}^{-1}$

$\omega_{a, \text { Co }} \quad$ Counter-flow air humidity ratio, $\mathrm{kg} \cdot \mathrm{kg}^{-1}$

$\omega_{a, C r} \quad$ Cross-flow air humidity ratio, $\mathrm{kg} \cdot \mathrm{kg}^{-1}$

$\omega_{a}^{i, j} \quad$ Air control volume humidity ratio in row $i$ and column $j, \mathrm{~kg} \cdot \mathrm{kg}^{-1}$

$\omega_{a, i} \quad$ Inlet air humidity ratio, $\mathrm{kg} \cdot \mathrm{kg}^{-1}$

$\zeta^{i, j} \quad$ solution control volume concentration in row $i$ and column $j, \mathrm{~mol} \cdot \mathrm{kg}^{-1}$

$\xi_{\text {Co }} \quad$ Counter-flow ratio of latent heat transfer to total heat transfer

$\xi_{\mathrm{Cr}} \quad$ Cross-flow ratio of latent heat transfer to total heat transfer

Subscripts

a Air

Co Counter-flow

$\mathrm{Cr} \quad$ Cross-flow

$i \quad$ Inlet

o Outlet

$s \quad$ Solution

LHT Latent heat transfer

SHT Sensible heat transfer

mt Moisture transfer

$P \quad$ Constant pressure

Superscripts

$i \quad$ The $i$ th control volume

$j \quad$ The $j$ th control volume

Greek symbols

$\omega \quad$ Humidity ratio, $\mathrm{kg} \cdot \mathrm{kg}^{-1}$

$\zeta \quad$ Solution concentration, $\mathrm{mol} \cdot \mathrm{kg}^{-1}$

$\beta \quad$ Packing material porosity

$\rho_{a} \quad$ Air density, $\mathrm{kg} \cdot \mathrm{m}^{-3}$

$\rho_{s} \quad$ Solution density, $\mathrm{kg} \cdot \mathrm{m}^{-3}$

$\xi \quad$ The ratio of latent heat transfer to total heat transfer 


\section{Appendix A}

Table A1. The calculated and experimental values of cross-flow HST.

\begin{tabular}{|c|c|c|c|c|c|c|c|c|c|}
\hline Time & $\mathrm{T}_{\mathrm{a}, \mathrm{i}}^{\mathrm{E}}\left({ }^{\circ} \mathrm{C}\right)$ & $\mathrm{T}_{\mathrm{s}, \mathrm{i}}^{\mathrm{E}}\left({ }^{\circ} \mathrm{C}\right)$ & $\omega_{\mathrm{a}, \mathrm{i}}^{\mathrm{E}}(\mathrm{kg} / \mathrm{kg})$ & $\mathbf{T}_{\mathbf{a}, \mathbf{o}}^{\mathrm{E}}\left({ }^{\circ} \mathrm{C}\right)$ & $\mathbf{T}_{\mathbf{a}, \mathbf{o}}^{\mathrm{C}}\left({ }^{\circ} \mathbf{C}\right)$ & $\mathbf{T}_{\mathbf{s}, \mathbf{o}}^{\mathrm{E}}\left({ }^{\circ} \mathbf{C}\right)$ & $\mathbf{T}_{\mathbf{s}, \mathbf{o}}^{\mathrm{C}}\left({ }^{\circ} \mathbf{C}\right)$ & $\omega_{\mathrm{a}, \mathrm{o}}^{\mathrm{E}}(\mathrm{kg} / \mathrm{kg})$ & $\omega_{\mathrm{a}, \mathrm{o}}^{\mathrm{C}}(\mathrm{kg} / \mathrm{kg})$ \\
\hline $14: 30$ & 11.25 & 2.17 & 0.00627 & 6.91 & 6.58 & 3.48 & 3.5 & 0.00546 & 0.00535 \\
\hline $14: 35$ & 11.20 & 2.32 & 0.00624 & 7.19 & 7.18 & 3.47 & 3.47 & 0.00570 & 0.00562 \\
\hline $14: 40$ & 11.30 & 2.15 & 0.00626 & 7.44 & 7.58 & 3.49 & 3.49 & 0.00583 & 0.00578 \\
\hline $14: 50$ & 11.18 & 2.24 & 0.00624 & 7.24 & 7.03 & 3.51 & 3.49 & 0.00567 & 0.00579 \\
\hline 14:55 & 11.20 & 2.16 & 0.00622 & 6.64 & 6.78 & 3.5 & 3.51 & 0.00547 & 0.00563 \\
\hline 15:00 & 11.18 & 2.25 & 0.00619 & 6.51 & 6.27 & 3.49 & 3.51 & 0.00543 & 0.00528 \\
\hline $15: 15$ & 11.20 & 2.15 & 0.00623 & 6.18 & 6.32 & 3.51 & 3.50 & 0.00532 & 0.0053 \\
\hline $15: 20$ & 11.15 & 2.11 & 0.00617 & 6.15 & 6.43 & 3.5 & 3.48 & 0.00531 & 0.00515 \\
\hline $15: 25$ & 11.25 & 2.23 & 0.00625 & 6.1 & 6.07 & 3.51 & 3.52 & 0.00529 & 0.00514 \\
\hline $15: 30$ & 11.20 & 2.26 & 0.00621 & 6.08 & 6.19 & 3.53 & 3.52 & 0.00529 & 0.00528 \\
\hline $15: 35$ & 11.18 & 2.23 & 0.00617 & 6.08 & 6.13 & 3.55 & 3.52 & 0.00529 & 0.00537 \\
\hline $15: 40$ & 11.22 & 2.25 & 0.00620 & 6.1 & 6.32 & 3.56 & 3.59 & 0.00530 & 0.00537 \\
\hline 16:05 & 11.05 & 2.23 & 0.00611 & 6.18 & 6.35 & 3.52 & 3.5 & 0.00533 & 0.00548 \\
\hline $16: 10$ & 11.27 & 2.14 & 0.00616 & 6.23 & 6.29 & 3.53 & 3.54 & 0.00534 & 0.00537 \\
\hline $16: 15$ & 11.10 & 2.33 & 0.00613 & 6.26 & 6.30 & 3.55 & 3.58 & 0.00535 & 0.00522 \\
\hline $16: 20$ & 11.39 & 2.3 & 0.00617 & 6.41 & 6.45 & 3.56 & 3.54 & 0.00541 & 0.00528 \\
\hline $16: 25$ & 11.49 & 2.3 & 0.00621 & 6.51 & 6.39 & 3.54 & 3.54 & 0.00545 & 0.00543 \\
\hline $16: 30$ & 11.37 & 2.27 & 0.00614 & 6.56 & 6.26 & 3.52 & 3.51 & 0.00547 & 0.00534 \\
\hline $16: 35$ & 11.39 & 2.28 & 0.00617 & 6.56 & 6.31 & 3.53 & 3.51 & 0.00547 & 0.00553 \\
\hline $16: 40$ & 11.39 & 2.2 & 0.00616 & 6.54 & 6.31 & 3.52 & 3.5 & 0.00545 & 0.00561 \\
\hline $16: 45$ & 11.25 & 2.28 & 0.00614 & 6.54 & 6.40 & 3.53 & 3.56 & 0.00545 & 0.00534 \\
\hline $16: 50$ & 11.22 & 2.28 & 0.00612 & 6.54 & 6.50 & 3.52 & 3.53 & 0.00545 & 0.00558 \\
\hline $16: 55$ & 11.15 & 2.28 & 0.00610 & 6.56 & 6.47 & 3.51 & 3.49 & 0.00547 & 0.00535 \\
\hline
\end{tabular}


Table A1. Cont.

\begin{tabular}{|c|c|c|c|c|c|c|c|c|c|}
\hline Time & $\mathbf{T}_{\mathbf{a}, \mathbf{i}}^{\mathrm{E}}\left({ }^{\circ} \mathrm{C}\right)$ & $\mathrm{T}_{\mathrm{s}, \mathrm{i}}^{\mathrm{E}}\left({ }^{\circ} \mathrm{C}\right)$ & $\omega_{\mathrm{a}, \mathrm{i}}^{\mathrm{E}}(\mathrm{kg} / \mathbf{k g})$ & $\mathbf{T}_{\mathbf{a}, \mathbf{o}}^{\mathrm{E}}\left({ }^{\circ} \mathbf{C}\right)$ & $\mathbf{T}_{\mathbf{a}, \mathbf{o}}^{\mathrm{C}}\left({ }^{\circ} \mathbf{C}\right)$ & $\mathbf{T}_{\mathbf{s}, \mathbf{o}}^{\mathrm{E}}\left({ }^{\circ} \mathbf{C}\right)$ & $\mathbf{T}_{\mathbf{s}, \mathbf{o}}^{\mathrm{C}}\left({ }^{\circ} \mathbf{C}\right)$ & $\omega_{\mathrm{a}, \mathrm{o}}^{\mathrm{E}}(\mathrm{kg} / \mathrm{kg})$ & $\omega_{a, 0}^{C}(k g / k g)$ \\
\hline $17: 00$ & 10.83 & 2.32 & 0.00610 & 6.48 & 6.16 & 3.52 & 3.52 & 0.00545 & 0.00534 \\
\hline 17:05 & 11.01 & 2.26 & 0.00613 & 6.51 & 6.49 & 3.5 & 3.53 & 0.00546 & 0.00557 \\
\hline $17: 10$ & 11.08 & 2.15 & 0.00618 & 8.17 & 7.98 & 3.5 & 3.53 & 0.00597 & 0.00607 \\
\hline $17: 15$ & 11.42 & 2.27 & 0.00621 & 7.04 & 6.81 & 3.51 & 3.49 & 0.00556 & 0.00544 \\
\hline $17: 20$ & 11.54 & 2.18 & 0.00623 & 7.07 & 6.91 & 3.49 & 3.46 & 0.00557 & 0.0054 \\
\hline $17: 25$ & 11.32 & 2.29 & 0.00618 & 7.09 & 7.06 & 3.5 & 3.48 & 0.00559 & 0.00562 \\
\hline $17: 30$ & 11.27 & 2.22 & 0.00618 & 7.12 & 6.97 & 3.52 & 3.51 & 0.00559 & 0.00557 \\
\hline $17: 35$ & 11.22 & 2.2 & 0.00615 & 7.14 & 7.40 & 3.53 & 3.56 & 0.00561 & 0.00576 \\
\hline $17: 40$ & 11.20 & 2.22 & 0.00622 & 7.32 & 7.37 & 3.53 & 3.52 & 0.00568 & 0.00563 \\
\hline $17: 45$ & 11.18 & 2.28 & 0.00623 & 7.34 & 7.58 & 3.54 & 3.51 & 0.00568 & 0.00575 \\
\hline $17: 50$ & 11.42 & 2.2 & 0.00623 & 7.57 & 7.91 & 3.55 & 3.55 & 0.00577 & 0.00562 \\
\hline $17: 55$ & 11.42 & 2.17 & 0.00622 & 7.62 & 7.78 & 3.54 & 3.55 & 0.00580 & 0.00589 \\
\hline 18:00 & 11.25 & 2.27 & 0.00617 & 7.65 & 7.76 & 3.56 & 3.56 & 0.00580 & 0.00577 \\
\hline 18:05 & 11.22 & 2.23 & 0.00623 & 7.7 & 7.82 & 3.57 & 3.58 & 0.00581 & 0.00585 \\
\hline 18:10 & 11.30 & 2.27 & 0.00625 & 7.75 & 7.61 & 3.55 & 3.58 & 0.00583 & 0.00571 \\
\hline 18:15 & 11.35 & 2.23 & 0.00626 & 7.8 & 8.11 & 3.53 & 3.55 & 0.00585 & 0.00599 \\
\hline
\end{tabular}




\section{References}

1. Cui, H.; Li, N.; Peng, J.; Cheng, J.; Li, S. Study on the dynamic and thermal performances of a reversibly used cooling tower with upward spraying. Energy 2016, 96, 268-277. [CrossRef]

2. Cui, H.; Li, N.; Peng, J.; Yin, R.; Li, J.; Wu, Z. Investigation on the thermal performance of a novel spray tower with upward spraying and downward gas flow. Appl. Energy 2018, 231, 12-21. [CrossRef]

3. Cui, H.; Li, N.; Wang, X.; Peng, J.; Li, Y.; Wu, Z. Optimization of reversibly used cooling tower with downward spraying. Energy 2017, 127, 30-43. [CrossRef]

4. Huang, S.; Ye, Y.; Han, X.; Zuo, W.; Zhang, X.; Jiang, L. Performance evaluation of heating tower heat pump systems over the world. Energy Convers. Manag. 2019, 186, 500-515. [CrossRef]

5. Man, Y.; Han, Y.; Hu, Y.; Yang, S.; Yang, S. Synthetic natural gas as an alternative to coal for power generation in China: Life cycle analysis of haze pollution, greenhouse gas emission, and resource consumption. J. Clean. Prod. 2016, 172, 2503-2512. [CrossRef]

6. Zhang, Q.; Wu, J.; Zhang, G.; Zhou, J.; Guo, Y.; Shen, W. Calculations on performance characteristics of counterflow Reversibly Used Cooling Towers. Int. J. Refrig. 2012, 35, 424-433. [CrossRef]

7. Chen, X.; Sun, F.; Chen, Y.; Gao, M. New retrofit method to improve the thermal performance of natural draft wet cooling towers based on the reconstruction of the aerodynamic field. Int. J. Heat Mass Transf. 2019, 132, 671-680. [CrossRef]

8. Jahangiri, A.; Borzooee, A.; Armoudli, E. Thermal performance improvement of the three aligned natural draft dry cooling towers by wind breaking walls and flue gas injection under different crosswind conditions. Int. J. Therm. Sci. 2019, 137, 288-298. [CrossRef]

9. Tan, K.; Deng, S. A numerical analysis of heat and mass transfer inside a reversibly used water cooling tower. Build. Environ. 2003, 38, 91-97. [CrossRef]

10. Tan, K.; Deng, S. A simulation study on a water chiller complete with a desuperheater and a reversibly used water cooling tower (RUWCT) for service hot water generation. Build. Environ. 2002, 37, 741-751. [CrossRef]

11. Zhang, L.; Wei, H.; Zhang, X. Theoretical analysis of heat and mass transfer characteristics of a counter-flow packing tower and liquid desiccant dehumidification systems based on entransy theory. Energy 2017, 141, 661-672. [CrossRef]

12. Zhang, L.; Liu, X.; Wei, H.; Zhang, X. Experimental study and analysis of heat and mass transfer ability of counter-flow packing tower and liquid desiccant dehumidification system. Energy Build. 2018, 158, 150-161. [CrossRef]

13. Vo, T.Q.; Kim, B.H. Interface thermal resistance between liquid water and various metallic surfaces. Int. J. Precis. Eng. Manuf. 2015, 16, 1341-1346. [CrossRef]

14. Guo, Y.; Surblys, D.; Kawagoe, Y.; Matsubara, H.; Liu, X.; Ohara, T. A molecular dynamics study on the effect of surfactant adsorption on heat transfer at a solid-liquid interface. Int. J. Heat Mass Transf. 2019, 135, 115-123. [CrossRef]

15. Surblys, D.; Kawagoe, Y.; Shibahara, M.; Ohara, T. Molecular dynamics investigation of surface roughness scale effect on interfacial thermal conductance at solid-liquid interfaces. J. Chem. Phys. 2019, 150. [CrossRef]

16. Tan, K.; Deng, S. A method for evaluating the heat and mass transfer characteristics in a reversibly used water cooling tower ( RUWCT ) for heat recovery. Int. J. Refrig. 2002, 25, 552-561.

17. Huang, S.; Lv, Z.; Liang, C.; Zhang, X. Experimental study of heat and mass transfer characteristics in a cross-flow heating tower. Int. J. Refrig. 2017, 77, 116-127. [CrossRef]

18. Wang, Z.; Zhang, X.; Li, Z. Investigation on the coupled heat and mass transfer process between extremely high humidity air and liquid desiccant in the counter-flow adiabatic packed tower. Int. J. Heat Mass Transf. 2017, 110, 898-907. [CrossRef]

19. Song, X.; Zhang, L.; Zhang, X. NTUm-based optimization of heat or heat pump driven liquid desiccant dehumidification systems regenerated by fresh air or return air. Energy 2018, 158, 269-280. [CrossRef]

20. Wen, X.; Liang, C.; Zhang, X. Experimental study on heat transfer coefficient between air and liquid in the cross-flow heat-source tower. Build. Environ. 2012, 57, 205-213. [CrossRef]

21. Huang, Y.; Ge, F.; Wang, C.; Hu, Z. Numerical study on the heat and mass transfer characteristics of the open-type cross-flow heat-source tower at low ambient temperature. Int. J. Heat Mass Transf. 2019, 145, 118756. [CrossRef] 
22. Liang, C.; Wen, X.; Liu, C.; Zhang, X. Performance analysis and experimental study of heat-source tower solution regeneration. Energy Convers. Manag. 2014, 85, 596-602. [CrossRef]

23. Li, W.; Wang, H.; Wang, J.; Duan, C.; Zhao, Y. Effect mechanism of exit-water temperature distribution characteristics on the anti-freezing of natural draft dry cooling tower. Appl. Therm. Eng. 2019, 161. [CrossRef]

24. Liu, X.H.; Jiang, Y.; Qu, K.Y. Heat and mass transfer model of cross flow liquid desiccant air dehumidifier/regenerator. Energy Convers. Manag. 2007, 48, 546-554. [CrossRef]

25. Qi, X.; Liu, Z.; Li, D. Performance characteristics of a shower cooling tower. Energy Convers. Manag. 2007, 48, 193-203. [CrossRef]

26. Zheng, S. Experimental Study of Heat Transfer Performance of Mechanical Draft Salt-water Cooling Tower.pdf; Zhejiang University: Hangzhou, China, 2012.

27. Conde, M.R. Properties of aqueous solutions of lithium and calcium chlorides: Formulations for use in air conditioning equipment design. Int. J. Therm. Sci. 2004, 43, 367-382. [CrossRef]

28. Al-Farayedhi, A.A.; Gandhidasan, P.; Al-Mutairi, M.A. Evaluation of heat and mass transfer coefficients in a gauze-type structured packing air dehumidifier operating with liquid desiccant. Int. J. Refrig. 2002, 25, 330-339. [CrossRef]

29. Lu, J.; Li, W.; Li, Y.; Zeng, L.; Yang, L.; Xie, L.; Li, Q.; Wang, M. Numerical study on heat and mass transfer characteristics of the counter-flow heat-source tower (CFHST). Energy Build. 2017, 145, 318-330. [CrossRef]

(C) 2020 by the authors. Licensee MDPI, Basel, Switzerland. This article is an open access article distributed under the terms and conditions of the Creative Commons Attribution (CC BY) license (http://creativecommons.org/licenses/by/4.0/). 